\title{
Growth of long III-As NWs by Hydride Vapor Phase Epitaxy
}

\author{
Evelyne Gil ${ }^{1,2}$, Yamina Andre ${ }^{1,2,3}$ \\ ${ }^{1}$ Université Clermont Auvergne, CNRS, SIGMA Clermont, Institut Pascal, F-63000 Clermont-Ferrand, France \\ 2 ITMO University, Kronverkskiy pr. 49, 197101 St. Petersburg, Russia \\ ${ }^{3}$ Department of Engineering Physics, McMaster University, Hamilton, Ontario L8S4L7, Canada
}

E-mail: evelyne.gil@uca.fr; yamina.andre@uca.fr

Received xxxxxx

Accepted for publication $\mathrm{xxxxxx}$

Published xxxxxx

\section{Outline}

Abstract

General Introduction

I. Thermodynamics and kinetics of HVPE growth

II. GaAs NWs grown by Au-catalysed VLS-HVPE

II.1. Brief recall of the issues of early growth experiments of GaAs NWs

II.2. Long untapered rodlike cubic GaAs NWs

II.3. The polytypism issue in GaAs NWs with diameter less than $10 \mathrm{~nm}$

III. Integration of GaAs NWs on silicon substrate

III.1. Introduction

III.2. Au-catalysed VLS-HVPE of GaAs NWs on Si: the nucleation issue

III.3. Au-catalysed VLS growth of GaAs:Si NWs on Si: the doping issue

IV. Self-catalysed growth of GaAs and InAs NWs on silicon substrate

IV.1. Thermodynamic conditions to form Ga and In liquid droplets from chloride gaseous molecules

IV.2. Self-catalysed growth of GaAs NWs on $\mathrm{Si}$

IV.3. Growth of InAs NWs on Si

Summary

Abbreviation: nanowire=NW; nanowires=NWs; vapor liquid solid=VLS; vapor solid=VS.

\begin{abstract}
In this review paper, we focus on the contribution of hydride vapor phase epitaxy (HVPE) to the growth of III-As nanowires (NWs). HVPE is the third epitaxial technique involving gaseous precursors together with molecular beam epitaxy (MBE) and metal-organic VPE (MOVPE) to grow III-V semiconductor compounds. Although a pioneer in the growth of III-V epilayers, HVPE arrived on the scene of NW growth the very last. Yet, HVPE brought different and interesting insights to the topic since HVPE is a very reactive growth system, exhibiting fast growth property, while growth is governed by the temperature-dependent kinetics of surface mechanisms. After a brief review of the specific attributes of HVPE growth, we first feature the innovative polytypism-free crystalline quality of cubic GaAs NWs grown by Au-assisted vapor-liquid-solid (VLS) epitaxy, on exceptional length and for radii down to $6 \mathrm{~nm}$. We then move to the integration of III-V NWs with silicon. Special emphasis is placed on the nucleation issue experienced by both Au-assisted VLS MOVPE and HVPE, and a model demonstrates that the presence of Si atoms in the liquid droplets suppresses nucleation of NWs unless a high
\end{abstract}


Ga concentation is reached in the catalyst droplet. The second known issue is the amphoteric behavior of $\mathrm{Si}$ when it is used as doping element for GaAs. On the basis of compared MBE and HVPE experimental data, a model puts forward the role of the As concentration in the liquid Au-Ga-As-Si droplets to yield p-type (low As content) or n-type (high As content) GaAs:Si NWs. We finally describe how self-catalysed VLS growth and condensation growth are implemented by HVPE for the growth of GaAs and InAs NWs on Si.

Keywords: HVPE, GaAs, InAs, nanowires 


\section{General introduction}

Semiconductor crystals have been synthesized for more than 60 years by means of epitaxial growth techniques, driven by the societal need for information and communication technologies. The whole story started with the controlled growth of bulk 3D millimeter scale crystals [1,2] and planar 2D thick buffer layers [3], followed by the race to reduce thicknesses of the 2D epilayers and control their stacking in low dimensionality heterostructures, including quantum wells and quantum dots, at the heart of microelectronic and optoelectronic devices. Together with these planar geometries, morphology-controlled 3D semiconductor structures were grown at the micrometer and submicrometer scales such as gratings, rods, tips, but also whiskers, to end with filamentary 1D nanowires. Whatever the geometry, shape, dimension of the epilayers or structures, the issues at stake are always the same: defect-free growth, control of the chemical composition of the layers, control of the crystal phase, control of the doping, control of the abruptness of interfaces in heterostructures, control of the facet growth anisotropy when it comes to the synthesis of $3 \mathrm{D}$ structures.

Three epitaxial processes are being implemented to grow the diversity of these objects: liquid phase epitaxy (LPE) [46], vapor phase epitaxy (VPE) and molecular beam epitaxy (MBE). MBE and metal-organic vapor phase epitaxy (MOVPE) are the most widespread growth techniques for III$\mathrm{V}$ compounds since the 1980s. The prevalence of MOVPE and MBE is still at play when it comes to nanowire (NW) growth. NWs are synthesized by a wide range of methods: top-down photolitography $[7,8]$, but above all bottom-up catalyst-free selective area growth (SAG) and catalyst-assisted vaporliquid-solid (VLS) and vapor-solid-solid (VSS) growth. Whatever the route, either vapor-solid condensation (in SAG) or liquid-solid solidification (in VLS), the main growth techniques involved in the synthesis of III $(\mathrm{Ga}, \mathrm{In})-\mathrm{V}(\mathrm{P}, \mathrm{As})$ NWs are still MBE and MOVPE. MOVPE is often considered as the most promising for the industrial mass manufacture of semiconductor NW arrays. First micro- and nano-sized wires were synthesized for Si and III-V materials by VLS growth $[9,10]$. Continuous efforts have been put forth into catalystassisted VLS growth of III-V NWs and most commonly used GaAs NWs for more than fifteen years. VLS growth is particularly well mastered nowadays for both MBE and MOVPE epitaxial tools and enables growth of complex NW structures, including ordered arrays of NWs by catalyzedselective area growth on patterned substrates [11-15].We invite the reader to consult some reviews and books coping with growth, properties and applications of semiconductor NWs [16-37].

Indeed, VPE processes involving chloride (e.g., not metalorganic) gaseous growth precursors were the very first vapor phase epitaxial techniques developed in the 1960s and 1970s for the growth of III-V semiconductor layers [2,38-40]. Yet, chloride-based growth techniques entered the nanowire growth scene the last by far. In hydride VPE (HVPE), the anion elements are transported by gaseous hydrides such as $\mathrm{AsH}_{3}$ for III-As compounds, but the specific attribute of HVPE growth is the use of chloride molecules for supplying the cation elements $\mathrm{Ga}$ or $\mathrm{In}$. These volatile chloride $\mathrm{GaCl}$ or $\mathrm{InCl}$ precursors have a direct impact on the reactor design and the thermodynamic conditions of growth. HVPE is a hot wall technique to ensure the stability of the chloride gaseous species. The growth reactions involving chloride precursors are exothermic while they are endothermic for MOVPE. The growth temperature is about $100^{\circ} \mathrm{C}$ higher for $\mathrm{HVPE}$ than it is for MOVPE or MBE for the same grown material. HVPE makes use of high partial pressures of precursors, which results in fast growth with some $30-50 \mu \mathrm{m} / \mathrm{h}$ for standard growth rate, up to more than $100 \mu \mathrm{m} / \mathrm{h}$ with a record at $300 \mu \mathrm{m} / \mathrm{h}$ for GaAs layers [41].

These features, high material input and fast growth, certainly justified the reluctance to use HVPE for the growth of small size objects. Moreover, by the time of the first VLS processes implemented in MBE and MOVPE at $400-600^{\circ} \mathrm{C}$ for the growth of GaAs NWs involving gold as catalyst, the high temperature needed for HVPE growth of GaAs $\left(700^{\circ} \mathrm{C}\right)$ was considered incompatible with a GaAs solidification from the triple VLS phase. Was HVPE worth the audience for current semiconductor issues, especially growth of NWs, arrays of NWs, nay integration of NW arrays with silicon? If we were to retain only two salient properties of HVPE, of course in addition to the high growth rate property, it would be: i) perfect selective growth capability, ii) the ability to reach large crystal growth anisotropy yielding unusual and high aspect ratio structures. The point was to apply these attributes to grow and shape matter at the nanometer scale. As a matter of fact, the road was drawn with the work of Lieber's group with the first demonstration of millimeter-long silicon nanowires grown at some $30 \mu \mathrm{m} / \mathrm{min}$ [42].

In this review paper, we address HVPE growth of III-V NWs. A brief analysis of HVPE thermodynamics is undertaken in section I, together with a discussion of the growth mechanisms and significant kinetic features of the growth of III-V by HVPE. Section II describes the ability of HVPE to grow high crystal quality GaAs NWs with high aspect ratio on GaAs substrates, by VLS-HVPE assisted by gold. Section III moves to the integration of GaAs NWs on silicon substrates by Au-catalysed VLS growth. Special emphasis is placed on the nucleation issue and on the doping of GaAs NWs with the silicon element, solving the enigma of n-type or p-type doping encountered with Si depending on the growth technique. Integration of GaAs and InAs NWs on $\mathrm{Si}$ by self-catalysed VLS growth is discussed in section IV. We finally summarize the input of HVPE to the synthesis of III-V NWs. 


\section{Thermodynamics and kinetics of HVPE growth}

The growth of (Ga,In)-As layers by HVPE involves gaseous $\mathrm{GaCl}$ and $\mathrm{InCl}$ molecules synthesized inside the reactor in an upstream zone, by the use of $\mathrm{HCl}$ flows reacting with separate $\mathrm{Ga}$ and In liquid sources at a temperature greater than $700^{\circ} \mathrm{C}$. As a matter of fact, HVPE is a hot wall reactor technique, needed to produce the III-Cl precursors and insure their stability downstream to the substrate. Element $\mathrm{V}$ is transported as arsine $\left(\mathrm{AsH}_{3}\right)$ which is completely decomposed into (As2, As4) gaseous molecules by entering the hot wall reactor [43]. HVPE is usually implemented at atmospheric pressure, with $\mathrm{H}_{2}$ as carrier gas (at $3 \mathrm{l} / \mathrm{min}$ ). One of the specific attributes of HVPE is that the substrate surface interacts with a complex vapor composed of III-Cl, $\mathrm{HCl}, \mathrm{H}_{2}$ and $\mathrm{As}_{4} / \mathrm{As}_{2}$, with the last two species being considered at equilibrium. In HVPE, we discuss results as a function of the III/V ratio calculated as the ratio between the partial pressure of gaseous III-Cl over the partial pressure of gaseous As4 interacting with the substrate surface in the growth zone. Note that for the temperature range set for the growth of GaAs or InAs, the partial pressure of $\mathrm{As}_{4}$ is a hundred times greater than the As2 partial pressure.

III-As deposition can be summarized by the global reaction:

$$
\frac{1}{4} \mathrm{As}_{4(\mathrm{~g})}+\mathrm{III}-\mathrm{Cl}_{(\mathrm{g})}+\frac{1}{2} \mathrm{H}_{2(\mathrm{~g})} \rightleftarrows \mathrm{III}-\mathrm{As}_{(\mathrm{c})}+\mathrm{HCl}_{(\mathrm{g})}
$$

where index $\mathrm{g}$ is assigned to gaseous molecules and index $\mathrm{c}$ is for crystalline species.

HVPE is known as a near-equilibrium condensation process: one can understand it as reacting almost immediately upon an increase of the supersaturation of the vapor phase that causes the return to equilibrium, which produces the solid [44]. On decreasing the supersaturation, for instance by the use of additional $\mathrm{HCl}$ in the vapor phase, reversible processes occur at the vapor-solid interface due to the volatility of the chlorides. First consequence is that HVPE features very fast growth (condensation growth rate ranging from 3 to 100 $\mu \mathrm{m} / \mathrm{h}$ ) upon setting high material input of growth precursors. As a matter of fact, III-As growth are implemented with partial pressures of $\mathrm{As}_{4}$ and III-Cl of some $7 \times 10^{-4} \mathrm{~atm}(70 \mathrm{~Pa})$ and $3 \times 10^{-3} \mathrm{~atm}(300 \mathrm{~Pa})$ above the substrate respectively. Please note that HVPE uses III/V ratio greater than one to compensate very substantial desorption of the volatile III-Cl precursors starting around $600^{\circ} \mathrm{C}$. The HVPE reactor design and the experimental parameters can be chosen in such a way that gas-phase mass transport is not a limiting factor for III-As layers growth. Growth is actually governed by the temperature-dependent kinetics of the surface mechanisms: adsorption and decomposition of growth precursors, desorption of by-products, and diffusion of ad-species, as demonstrated by the strong temperature dependence of the GaAs growth rate under standard growth conditions (Figure 1)

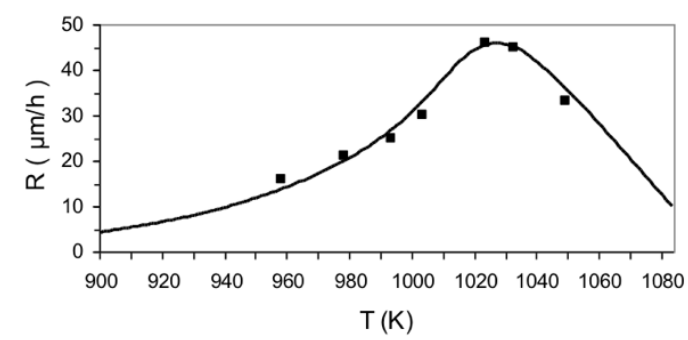

Figure 1. Growth of GaAs by HVPE: variation of the growth rate $R$ as a function of the temperature. At low temperature, growth is limited by the decomposition of adsorbed precursors, e.g., their dechlorination. As the temperature increases, $R$ increases according to an enhanced thermal activation of the dechlorination step, until desorption prevails upon adsorption of materials on the substrate surface for the highest temperatures. The strong dependence of $R$ with temperature demonstrates that HVPE growth is governed by kinetics and thermodynamics, and that it is not mass-transfer limited. It was also demonstrated that diffusion of the ad-species on the surface plays a negligible role with respect to the adsorption/desorption and dechlorination mechanisms [46].

$[45,46]$. Among the aforesaid surface kinetics involved in the HVPE process, the III-Cl growth precursor decomposition kinetics appears to be the slowest, so that it is considered as the actual limiting rate for HVPE growth [46]. Note that the decomposition kinetics of III-Cl precursors is still faster than that of other chemical precursors such as metal-organic ones. Record HVPE growth rate (such as $300 \mu \mathrm{m} / \mathrm{h}$ for GaAs [41]) is often associated with the use of high supersaturation conditions in the mind of growth physicists. As a matter of fact, HVPE is considered as a high supersaturation process, which is not true, because one may confuse high supersaturation and high material input. Indeed, the Gibbs free energy difference that maintains the stationary state between solid GaAs and a vapor composed of As4/As2 and volatile $\mathrm{GaCl}$ molecules is some $450 \mathrm{cal} / \mathrm{mol}$ at $715^{\circ} \mathrm{C}$, which is about eight times lower than the thermodynamic driving force for MOVPE and MBE [47]. It turns out that it is easy to supersaturate the vapor phase to yield high growth rates in HVPE. This highly reactive system needs very few material amount (10 sccm for the gaseous $\mathrm{AsH}_{3}$ flow, $10 \mathrm{sccm}$ for the gaseous $\mathrm{HCl}$ flow over the $\mathrm{Ga}$ source or the In source).

Here comes the first question about using fast growth for growing NWs, even by VLS-mediated growth. It is generally assumed that a high growth rate yields lower crystalline quality. Early HVPE experiments demonstrated that high quality epilayers had been grown at growth rates higher than $100 \mu \mathrm{m} / \mathrm{h}$ [41]. Use of rapid growth was addressed for the IV compounds with the synthesis of silicon and germanium NWs with lengths up to $30 \mu \mathrm{m}$ in a pioneer work [42]. Highly uniform millimeter-long $\mathrm{Si}$ NWs were successfully grown at a mean rate of $31 \mu \mathrm{m} / \mathrm{min}$ and used as building blocks to fabricate field effect transistor arrays consisting of some 100 devices per nanowire [48]. NWs, a few tens of micrometers long, provide larger surfaces to be functionalized, which is of 
great interest for sensor and detection applications [48][49]. Due to the rapid decomposition of the III-Cl growth precursors with respect to other chemical precursors, one could expect HVPE to be an efficient alternative tool for the synthesis of III-V alloy NWs with exceptional length at an acceptable growth rate, provided the control of the morphology and crystalline homogeneity of the nano-objects. Very interestingly, Joyce et al. used rapid growth rate in VLSMOVPE to synthesize less tapered, planar crystallographic defect-free III-V NWs [50]. The authors actually observed that increasing the precursor flows and consequently the growth rate, decreased the NW twin density [50]. One should promote untapered morphologies for laser applications where uniform diameters are expected to enhance the NW performance as a resonant cavity. All these results suggest that low defect density semiconductor NWs can be grown very fast.

When it comes to VLS growth, the second issue is related to temperature. HVPE growth of III-As compounds is implemented at some $715^{\circ} \mathrm{C}$ for GaAs and $650^{\circ} \mathrm{C}$ for InAs, the temperatures at which the thermal activated dechlorination of the III-Cl precursors works well. Investigating VLS in the HVPE environment addresses the question of how catalystassisted VLS could be carried out at such high temperatures. These usual process temperatures in HVPE result in high condensation planar growth rates (standard 30-40 $\mu \mathrm{m} / \mathrm{h}$ for growth on (001)). Another interest is to assess the competition between VLS solidification of NWs expected to take place in the $<111>$ B direction and condensation planar growth on the [001] direction. The first HVPE growth experiments of GaAs NWs described in the next section, answered these two questions.

Last point addresses morphology-controlled 3D micro- and nanostructures. Such morphology-controlled growth is usually carried out by selective area growth on patterned substrate. HVPE performs very well on that matter as volatile chloride precursors do not adsorb on masked areas whatever the geometry of the pattern, even on dark field patterns [51]. HVPE also gives access to the large growth anisotropy of current III-V crystals. The competition for precursors between masked and open areas being non existent, one can expect the $3 \mathrm{D}$ morphologies to be ruled by surface kinetics, that is by the intrinsic growth anisotropy of crystals. For convex growth, the shaping rule is: a face is all the more developed that it grows slowly. In a growth regime governed by surface kinetics, the growth rate of the faces can be set by varying the experimental parameters of the temperature and composition of the vapor phase, both III/V ratio and supersaturation with the use of additional $\mathrm{HCl}$. HVPE offers the possibility to set a large number of growth rate ratios as a wide range of growth rates are available whatever the orientation [44]. This huge anisotropy allows to shape structures with various morphologies and aspect ratios, in one-step short growth time, capitalizing upon the main advantage of the bottom-up approach: structures are defined by their crystalline properties with no scattering defects as typically induced by techniques involving etching. This is one of the key points of HVPE: as the growth is governed by surface kinetics, one can tailor experimental parameters to increase growth anisotropy, to generate high-aspect-ratio defect-free structures at the micrometer scale such as stripes [52], tips [53], and at the nanometer scale such as gratings of high aspect ratio stripes [51].

\section{GaAs NWs grown by Au-catalysed VLS-HVPE}

\section{II.1 Brief recall of the issues of early growth experiments of GaAs NWs}

As already quoted, the first bottom-up approach for the synthesis of NWs was the catalyst-assisted VLS growth as introduced by Wagner and Ellis in 1964 to explain the epitaxial growth of micron-sized Si whiskers [9]. The second fundamental work was provided by Hiruma et al. who demonstrated the feasibility of the VLS growth of III-V nanowhiskers [10]. In VLS growth, a suitable metal catalyst alloys with the metal atoms of the III-V surface introducing a local liquid-solid interface. The constituent materials are supplied from the vapor phase and incorporated into the metal catalyst which acts as a seed for the NW growth. For these pioneer studies, GaAs NWs were mostly grown from Au catalytic particles.

The period between 2000 and 2010 was a very dynamic production time for semiconductor NWs VLS growth. Let us cite major works implementing MBE [54-57], Chemical Beam Epitaxy (CBE) [58], Electron Beam Epitaxy (EBE) [59], and MOVPE [60-65]. The metallic clusters determine the shape and position of the NWs. Size-selected catalytic Au aerosol particles were manipulated by means of atomic force microscopy (AFM), in order to nucleate nano-whiskers in specific positions [66]. Patterning of the catalyst on the substrate surface was also carried out by electron beam lithography [67], or nano-imprint lithography [68], followed by catalyst evaporation and lift-off.

Whatever the structure device is, high material crystal quality is required. The control of the crystal phase of III-V NWs has been a challenging task for a while [69-72]. Indeed, GaAs NWs featured spontaneous zinc blende (ZB)-wurtzite (WZ) polytypism and stacking faults could form between alternating $\mathrm{WZ}$ and $\mathrm{ZB}$ layers along the $<111>$ axis of the NWs [73-77]. The issue of the crystal phase of NWs is not trivial. It is related to a complex combination of surface energy values, catalyst droplet contact angle, wetting of the NW side facets and applied growth conditions. In pioneering studies of Au-catalysed MOVPE, high V/III ratio and low temperature (T) were demonstrated to favor predominantly ZB NWs, while low V/III and high $\mathrm{T}$ were suitable for pure WZ [78,79]. Crystal phase engineering involving controlled axial stacking 
of $\mathrm{WZ}$ and $\mathrm{ZB}$ segments was addressed soon [80,81]. Lehmann et al. refined the conditions and showed that transitions between $\mathrm{ZB}$ and $\mathrm{WZ}$ were actually related to growth regimes being As-limited (ZB to WZ) or Ga-limited (WZ to ZB) [82]. The role of the droplet contact angle and wetting of NW side facets was clarified later, introducing distinct nucleation locations to yield WZ or ZB segments (see section II.3).

The first quote of wire growth by HVPE was actually found in 1993 [83]. InP wires were selectively grown on bare (001) GaAs substrates which were patterned with focused ion beam to create steps and kinks for further localised InP nucleation [84-86]. This was made possible because HVPE growth is orientation dependent as was said in the previous section; a diffusion controlled process is unefficient in that case. Ten years have passed before new work on NWs growth by HVPE was published. As a matter of fact, not only very few HVPE research groups are still active for III-As and III-P compounds (Wisconsin-Madison University in the USA; KTH (Sweden), Thales Research and Technology/Thales-Alcatel III-V Laboratory and Institut Pascal (France) in Europe), but also the HVPE high process temperature and fast growth property were considered as major issues for implementing VLS epitaxy of III-V NWs.

\section{II.2 Long untapered rodlike cubic GaAs NWs}

The first synthesis of GaAs NWs by Au-assisted VLS growth in the HVPE environment was reported in 2010 [87]. For this preliminary study, non optimum conditions were chosen like early MOVPE and MBE attempts: random Au distribution on the surface and (001) oriented GaAs substrates. $2 \mathrm{~nm}$-thick Au films were deposited on the substrates in an ultra-high vacuum (UHV) evaporator system at room temperature. The substrates were subsequently heated into the HVPE reactor from room temperature to growth temperature $\left(715^{\circ} \mathrm{C}\right)$. During this 20 -min step, the substrates were kept under an undersaturated As2/As4 atmosphere to favor the formation of $\mathrm{Ga}$ liquid droplets on the surface. This results in a rough $\mathrm{Au}-\mathrm{Ga}$ surface layer with a significant liquid $\mathrm{Ga}$ coverage, after decohesion of the $\mathrm{Au}$ film, random $\mathrm{Au}$ diffusion and self-assembly into Au-Ga particles of various diameters greater than $50 \mathrm{~nm}$. Note that for this very first HVPE study, non-optimum conditions were chosen like early MOVPE and MBE attempts: random Au distribution on the surface and (001) oriented GaAs substrates. The aim was to assess whether VLS could take place in a HVPE environment, in particular at high temperature that is needed to ensure the stability of the chloride precursors and their fast decomposition, and the competition between VLS expected to take place in the $<111>$ direction and standard condensation planar growth on (001). GaAs growth was implemented with a III/V ratio above the substrate of 5 , which yields a GaAs layer-by-layer growth rate of $38 \mu \mathrm{m} / \mathrm{h}$ on vicinal (001) GaAs substrates at $715^{\circ} \mathrm{C}$.

During the 15-min growth time, a complex growth system took place with i) the growth of a $2 \mathrm{D}$ rough layer $9 \mu \mathrm{m}$-thick on the substrate surface, ii) the growth of GaAs mesoscopic oriented scales corresponding to GaAs nucleation and growth from a $\mathrm{Ga}$ rich surface, iii) with $\mathrm{Au}-\mathrm{Ga}$ droplets randomly distributed on their faces from which wires were grown. As a matter of fact, an ensemble of parallel GaAs NWs were nucleated from the scales and grown at $35^{\circ}$ from the substrate (001) plan [87]. The NWs exhibited exceptional length, from $40 \mu \mathrm{m}$ to more than $100 \mu \mathrm{m}$ for a mean diameter of $120 \mathrm{~nm}$ as the result of the random formation of the Au-Ga droplets during the substrate pre-growth annealing. The NWs axial growth rate was greater than $100 \mu \mathrm{m} / \mathrm{h}$ (Figure 2) [87].

The second interesting feature was the perfect untapered morphology from bottom to top: NWs were rodlike $<111>B$ cubic ZB monocrystalline phase objects (Figure 2) [87]. These preliminar results were confirmed for NWs with lower diameter (Figure 2), where the defect-free and stacking faultfree cubic crystal structure was validated by HRTEM, photoluminescence and Raman spectroscopies [88]. The cubic structure was indeed expected for NWs with diameter greater than $30 \mathrm{~nm}$. HVPE reproduced on the matter the results obtained by Au-catalysed MBE and MOVPE. What was remarkable was the constant diameter and the $\mathrm{ZB}$ phase and crystal quality kept constant along several tens of micrometers for $<111>\mathrm{B}$ GaAs NWs. As a matter of fact, GaAs NWs grown by catalyst-assisted HVPE showed the highest aspect ratios, ranging from 800 to 1000 for diameter ranging from 50 to $130 \mathrm{~nm}$.

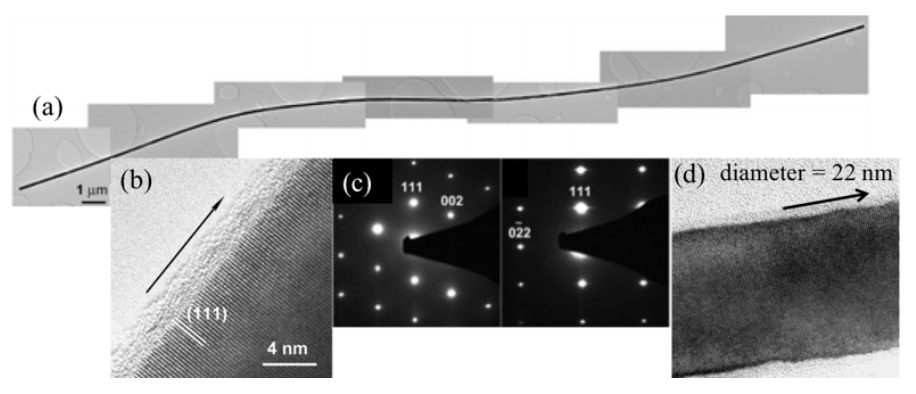

Figure 2. (a) TEM image of a $50 \mu \mathrm{m}$-long GaAs NW with a constant diameter of $120 \mathrm{~nm}$. (b) HRTEM image of the edge of a GaAs NW. The arrow shows the $<111>B$ growth direction. Wedge angles were determined around $60^{\circ}$. Amorphous native oxide covers the NW. (c) Electron diffraction patterns of a GaAs NW: left [-110], right [-211] zone axis in the cubic ZB structure [87]. (d) HRTEM image of a GaAs NW with a diameter of $22 \mathrm{~nm}$. All HRTEM images were taken along the [121] zone axis [88]. 
First insight of the growth mechanisms involved in Auassisted VLS-HVPE explains such aspect ratios. VLS-HVPE is supposed to occur preferentially via the adsorption of $\mathrm{GaCl}$ molecules on fully liquid Au-Ga-As droplets [88] at growth temperature higher than $700^{\circ} \mathrm{C}$, followed by fast decomposition and desorption of the $\mathrm{Cl}$ atoms in the $\mathrm{H}_{2}$ ambient atmosphere. The liquid phase seems plausible (VSS should be excluded) with respect to the process temperature and the observed NW high growth rate: a rich Ga content AuGa liquid phase takes place upon the pre-growth annealing of the Au-GaAs substrate, and then the wetting of the catalyst particle with Ga and As insures the NW extension. VLSHVPE GaAs NWs have uniform diameter from the base to the top, over length greater than $10 \mu \mathrm{m}$. A simple argument excludes any diffusion of growth precursors from the substrate surface along the nanowire sidewalls: the length of the wires is much longer than the surface diffusion length of whatever ad-species. If precursors diffused from the substrate surface, then one would have observed a larger base on the NWs. Indeed, the rapid condensation rate on the planar substrate (38 $\mu \mathrm{m} / \mathrm{h}$ ) is high enough to incorporate the incoming matter before migration towards the wires. If radial growth took place in VLS-HVPE, it would be fed through uniform adsorption of the precursors directly on the sidewalls of the NWs. Radial growth involves condensation when axial growth is based on solidification. The growth rate anisotropy between axial and radial growth is high enough to promote preferential axial development of the NWs and limited radial growth. The postgrowth energy dispersive X-ray spectroscopy (EDS) analysis showed a Ga content below $1 \%$ in the tip of grown NWs [88]. Such an after-growth low Ga content can be explained by a quick diffusion of the Ga element to the liquid-solid interface, as a consequence of the concentration gradient established between the droplet surface and the heterogeneous liquid-solid interface where a rapid solidification kinetics yields an almost complete and instantaneous consumption of the Ga species. Rapid Ga incorporation into the droplet is favored by the high dechlorination frequency: $\mathrm{GaCl}$ molecules are quickly decomposed, probably as soon as they adsorb on the surface of the Au-Ga-As droplet. Such a reactant decomposition kinetics-limited growth regime was also demonstrated for the VLS synthesis of millimeter-long Si NWs [48].

Let us now return to the link between the growth regime and the crystal homogeneity of the NWs. Changes in the shape of wires were observed when the growth mechanism switched from surface diffusion to direct impingement [57,89]. Plante et al. have shown that modifications of the crystal structure of NWs took place where growth by surface diffusion was dominant [54]. As already discussed, one expect VLS-HVPE to rely on a preferential axial growth mode through the catalyst droplet. The absence of competition between radial and axial growth, the latter one being very limited, almost non existent, favors the crystalline homogeneity of the NWs and probably the absence of twins. Nevertheless, it is not possible to conclude about VLS-HVPE and its capability to control crystal homogeneity unless growth of thin NWs of diameter less than $20 \mathrm{~nm}$ has been addressed, knowing that structure variations, from cubic to wurtzite, were observed for very thin GaAs NWs produced by MOVPE and MBE.

\section{II.3 The polytypism issue in GaAs NWs with diameter less than $10 \mathrm{~nm}$}

GaAs NWs grown by MOVPE or MBE with diameter lower than $30 \mathrm{~nm}$ were shown to exhibit a wurtzite structure with some ZB-WZ polytypism. The thinnest GaAs NWs published in 2009 were grown by VLS-MBE: NWs with diameter of 10 and $13 \mathrm{~nm}$ exhibing a WZ structure over length of $5 \mu \mathrm{m}$ with negligible intermixing of ZB stacking [90]. Thorough theoretical investigations of catalyst-assisted growth in the MBE and MOVPE processes have shown that suppression of nucleation at the triple phase line (TPL) (where the vapor, liquid and solid phases meet) helps to avoid ZBWZ polytypism under optimized growth conditions [75]. This model was supported by experimental data provided by the VLS-MBE process with the Ga-catalysed growth of GaAs NWs [91]. As a matter of fact, several groups confirmed that self-catalysed III-V NWs adopted the ZB phase much more often than Au-catalysed one [91-93]. Zamani et al. implemented polarity engineering to grow stacking disorder free (111)A-polar GaAs NWs under Ga-rich conditions in Gaassisted MBE [94].

It appeared interesting to follow the evolution of the crystalline phase of NWs grown in the HVPE environment for the peculiar radius range $(5-15 \mathrm{~nm})$ where uncontrolled polytypism and conversion to WZ in (111)B NWs took place. GaAs VLS-HVPE growth was carried out on Au-coated (001) GaAs substrates [95]. Au droplets with diameters ranging from 50 to $10 \mathrm{~nm}$ were formed after annealing at $715^{\circ} \mathrm{C}$ in the HVPE reactor of $\mathrm{Au} / \mathrm{GaAs}$ substrates where a nominal amount of $\mathrm{Au}$ equivalent to 0.1 monolayer was deposited. GaAs growth was carried out at $715^{\circ} \mathrm{C}$ for $30 \mathrm{~min}$ with a partial pressure of $\mathrm{GaCl}$ of $300 \mathrm{~Pa}$, a partial pressure of $\mathrm{As}_{4}$ of $71 \mathrm{~Pa}$ (partial pressure of As2 was $0.5 \mathrm{~Pa}$ ) and with a $\mathrm{H}_{2}$ vector flow of $3000 \mathrm{sccm}$ including additional $\mathrm{HCl}$ flow (at $50 \mathrm{~Pa}$ ) used to tune the supersaturation of the vapor phase $[45,46,52]$. These experimental parameters yielded a GaAs 2D planar growth rate of $38 \mu \mathrm{m} / \mathrm{h}$ and $20 \mu \mathrm{m} / \mathrm{h}$ on (001) and (111) $\mathrm{B}$ GaAs substrates, respectively.

Figure 3 shows the transmission electron microscopy (TEM) and high resolution TEM (HRTEM) images of a GaAs NW $14 \mu \mathrm{m}$ long with a constant radius of $15 \mathrm{~nm}$ grown by VLS-HVPE. Figures 3 (c) displays the HRTEM image of a NW with a radius of 5-6 nm, indexed in the cubic ZB structure (see the Fast Fourier Transform (FFT) image in Figure 3 (c)). NWs were grown in the $<111>\mathrm{B}$ direction, exhibiting stacking-fault free pure ZB phase over the lengths which could 
be observed on individual NWs, that is up to $20 \mu \mathrm{m}$. Contrary to the NWs with radii of $25 \mathrm{~nm}$ or above, which were found hexagonal with (211) facets [87], thinner NWs have a more complex faceting. The prevalence of (211) ZB facets makes the observed crystal phase purity even more surprizing, since it is known from different calculations [96-98] that these facets have a higher surface energy than (110) and therefore the formation of ZB structure is more energetically costly in this case. The defect-free area excludes a very narrow zone just beneath the droplet where structural instabilities take place due to unsteady conditions in the droplet upon stopping precursors at the end of growth, resulting in progressive decreasing of the Ga liquid supersaturation after consumption upon crystallization.

The unexpected ZB phase for GaAs NWs of 5-15 nm radii calls for discussion. It is predicted from equilibrium formation energies that pure $\mathrm{WZ}$ phase should form for a radius of the order of $10 \mathrm{~nm}$ regardless of the growth conditions [98,99]. In addition to these considerations related to intrinsic energetic morphological stability, crystal growth conditions play a major role through supersaturation state in the catalyst droplet which drives the nucleation path. The competition between the $\mathrm{ZB}$ and WZ structures is driven by the difference in the corresponding nucleation barriers rather than equilibrium energies of fully formed NWs. This increases the actual critical radius for the $\mathrm{ZB}$-to- $\mathrm{WZ}$ transition to the value of the order of several tens of nanometers depending on the growth conditions [96]. VLS-HVPE yields NW axial growth rate of $100 \mu \mathrm{m} / \mathrm{h}$ or higher, from liquid Au-Ga-As droplets with an original high percentage of Ga (higher than $30 \%$ if the droplets were pure binary Au-Ga alloys) [100].

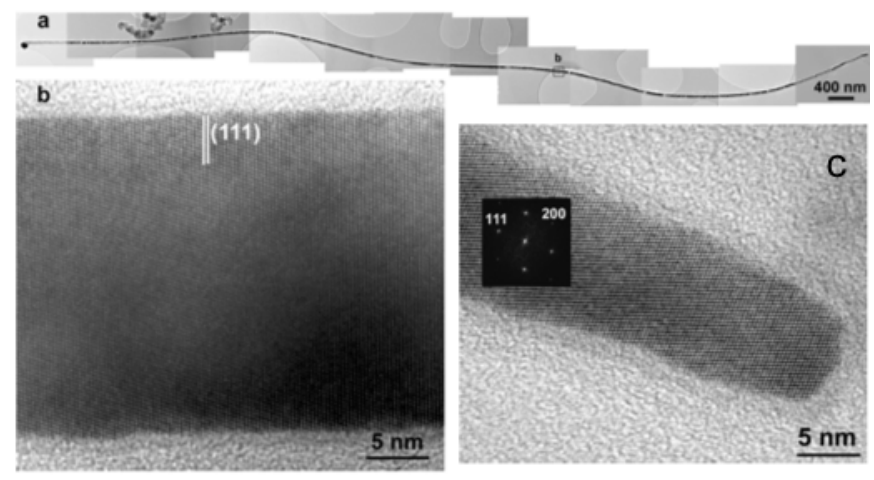

Figure 3. (a) TEM image of a GaAs NW $14 \mu \mathrm{m}$ long with a constant radius of $15 \mathrm{~nm}$ grown by Au-assisted VLS-HVPE at $715^{\circ} \mathrm{C}$. HRTEM images taken along the [00-1] zone axis of the above $\mathrm{NW}$ (b) and of a NW with a radius of 5-6 $\mathrm{nm}$ grown under the same conditions (c) [95].
In order to predict the crystal phase of NWs grown by Auassisted VLS-HVPE, a model was developed in two steps $[95,101]$. The first step expresses the liquid chemical potential of $\mathrm{GaAs}$ in an Au-Ga-As droplet with respect to the stoichiometric ZB solid:

$$
\Delta \mu=\mu_{3}^{1}+\mu_{5}^{1}-\mu_{35}^{\mathrm{S}}
$$

with $\mu_{3}^{1}$ and $\mu_{5}^{1}$ as the chemical potentials of Ga and As atoms in the liquid state respectively and $\mu_{35}^{\mathrm{S}}$ as the chemical potential of a GaAs pair in the solid state. $\mu_{3}^{1}$ is written as a function of the Ga concentration in the liquid droplet ( $\left.c_{3}\right)$ and is temperature-dependent. $\mu_{35}^{\mathrm{S}}$ and $\mu_{5}^{1}$ do not contain dependence on the droplet composition. $\mu_{5}^{1}$ is written as a function of the ratio between the As desorption flux and the As adsorption flux on the droplet surface. The prevalence of the WZ phase over ZB in VLS NWs requires that the $\Delta \mu$ value is larger than two critical chemical potentials. The first one corresponds to the equality of the nucleation barriers for the critical WZ and ZB nuclei at the TPL and the second to the equality of the nucleation barrier for the $\mathrm{WZ}$ nucleus at the TPL and the ZB nucleus in the center $(C)$ of the liquid-solid interface under the droplet. Consequently, the WZ structure forms when $\Delta \mu>\max \left(\Delta \mu_{\mathrm{TPL}} ; \Delta \mu_{\mathrm{C}}\right)$ with $\Delta \mu_{\mathrm{TPL}}$ and $\Delta \mu_{\mathrm{C}}$ written as a function of the bulk energy difference between the WZ and $\mathrm{ZB}$ structures, involving the surface energies of relevant $\mathrm{ZB}$ and WZ NW sidewall facets, the liquid-vapor surface energy of the droplet, the surface energy of the lateral solidliquid interface of a two-dimensional island, and the fraction of the island perimeter at the TPL. The critical curve $\max \left(\Delta \mu_{\mathrm{TPL}} ; \Delta \mu_{\mathrm{C}}\right)$ is shown in Figure 4 . It is seen that the critical chemical potential is limited by the $\Delta \mu_{\mathrm{TPL}}$ for the Ga concentrations lower than 0.36-0.51, depending on the ZB facet type, while for higher $c_{3}$, it is given by the $\Delta \mu_{\mathrm{C}}$, i.e., by the competition of the WZ TPL and the ZB C nucleation scenarios. Above $c_{3}=0.65$, the $\mathrm{WZ}$ phase formation is completely suppressed on surface energetic grounds due to a low surface energy of a Ga-rich droplet, as in the case of pure Ga catalyst [91]. Hence, the WZ phase should be observed for high chemical potentials and low Ga concentrations in the topleft corner, while the ZB phase dominates below the critical curves. Very importantly, the ZB phase should form for all $c_{3}>0.65$ actually regardless of the NW radius. This feature does not depend on the ZB facet type (i.e., (211) or (110)), because the nuclei are entirely surrounded by the liquid phase and do not feel the sidewalls. Therefore, the absolutely defectfree ZB phase of HVPE-grown GaAs NWs would be confirmed if we show that the Ga concentration in the droplets during growth is above 0.65 for all NWs.

Second step of the modelling writes the NW elongation rate $(\mathrm{dL} / \mathrm{dt})$ as a function of the kinetics of As atoms arriving to and leaving from an Au-Ga-As droplet. The actual Ga concentration during growth can be estimated by equating the 


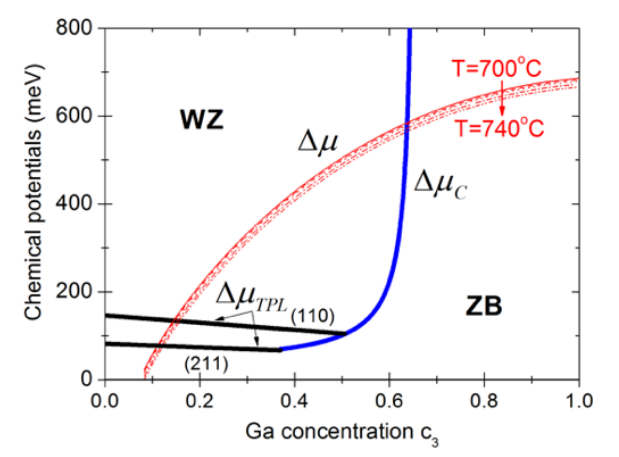

Figure 4. Chemical potential of GaAs in a liquid Au-Ga-As droplet during Au-catalysed VLS-HVPE of GaAs NWs for temperatures between 700 and $740^{\circ} \mathrm{C}$ (red lines) as a function of the Ga concentration in the droplet. It is compared to the critical chemical potentials $\Delta \mu_{T P L}$ and $\Delta \mu_{C}$. The WZ phase should be prevalent in the top-left corner, while the $\mathrm{ZB}$ structure forms below the two critical curves [95].

observed elongation rate (with the minimum of $100 \mu \mathrm{m} / \mathrm{h}$, or $28 \mathrm{~nm} / \mathrm{s}$ ) to the nucleation-mediated NW growth rate:

$$
\frac{\mathrm{dL}}{\mathrm{dt}}=\frac{3 \sqrt{3}}{2} \mathrm{R}^{2} \mathrm{~h} \times \mathrm{Ac}_{5} \sqrt{\frac{\Delta \mu}{\mathrm{k}_{\mathrm{B}} \mathrm{T}}} \exp \left(-\frac{\Delta \mathrm{G}_{*}}{\mathrm{k}_{\mathrm{B}} \mathrm{T}}\right)
$$

with $\mathrm{R}$ the radius of a two-dimensional nucleus of a monolayer height $\mathrm{h}, \mathrm{A}$ an unknown pre-factor in the Zeldovich nucleation rate, $c_{5}$ the As concentration in the droplet. $\Delta \mathrm{G}_{*}$ is the nucleation barrier for triangle two-dimensional nuclei of dimensions $\mathrm{R}$ and $\mathrm{h}$. All calculation details are given in reference [101]. The nucleation rates obtained at $715^{\circ} \mathrm{C}$ and $\mathrm{A}=7 \mathrm{~nm}^{-2} \mathrm{~s}^{-1}$ (as recommended by Glas et al., at temperatures near $600^{\circ} \mathrm{C}$ [102]) are shown by the red lines in Figure 5 for different NW radii from 5 to $50 \mathrm{~nm}$. It is seen that crossing points of these curves with the minimum experimental elongation rate of $28 \mathrm{~nm} / \mathrm{s}$ correspond to the values of $c_{3}$ which are systematically higher than 0.7 . If we increase the value of A by a huge factor of $10^{4}$ (which could partly be due to enhanced diffusivity of As at $715^{\circ} \mathrm{C}$ compared to $600^{\circ} \mathrm{C}$ ), the Ga concentration would still remain higher than 0.65 , as shown by the blue lines in Figure 5. In other words, the exceptional elongation rate in VLS-HVPE necessarily requires the droplet to be Ga-rich, which yields the pure $\mathrm{ZB}$ phase due to the suppression of the TPL nucleation on surface energetic grounds. This conclusion is robust with respect to variations in temperature $\left(700-740^{\circ} \mathrm{C}\right)$ and in the generally unknown pre-exponential factor A.

As a summary, record pure cubic phase $20 \mu \mathrm{m}$ long and 5 $\mathrm{nm}$ in radius GaAs NWs were grown by Au-assisted VLSHVPE [95]. It was demonstrated that VLS growth took place at high liquid supersaturation, yielding a $\mathrm{Ga}$ concentration higher than 0.5 in the Au-Ga-As droplets. The high Ga concentration decreases the surface energy of the droplets, which inhibits nucleation at the triple phase line, thus

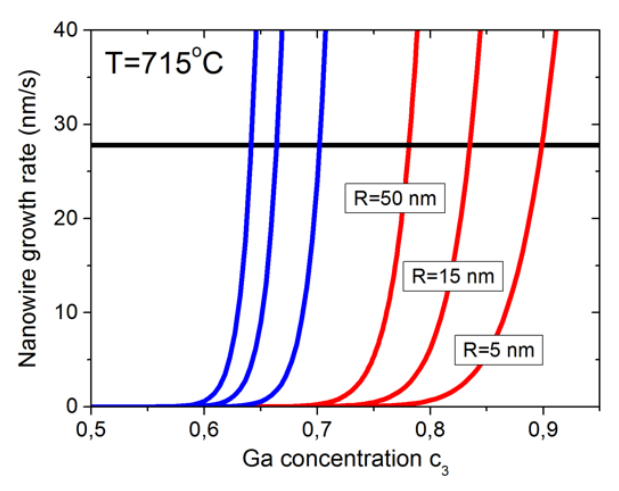

Figure 5. Axial growth rate variation of GaAs NWs grown by Aucatalysed VLS-HVPE at $715^{\circ} \mathrm{C}$ as a function of the Ga concentration in the catalyst droplet. Red and blue curves correspond to two values of the the pre-factor A that ranges the HVPE process, calculated for three values of NW radii $(5,15$ and $50 \mathrm{~nm})$. The experimental axial growth rate is $28 \mathrm{~nm} / \mathrm{s}$. It crosses the calculated curves for Ga concentration greater than 0.6, regardless of the As conditions and NW's radius. After Figure 4, NWs grown under such a high Ga supersaturation exhibit the $\mathrm{ZB}$ phase regardless of their radius [95].

preventing the formation of $\mathrm{WZ}$ structure regardless of the NW radius. These results confirmed the theoretical predictions of Glas, Dubrovskii et al., by providing experimental data with Ga-rich concentrations not readily accessible by the MBE and MOVPE processes. Recently, NW growth was followed in situ in transmission electron microscopes. Emphasis was placed on the values of the contact angle of the catalyst droplet that favor nucleation at the TPL $\left(90^{\circ}\right)$ yielding to the $\mathrm{WZ}$ phase, or favor the formation of a truncated facet at the liquid-solid interface which yields nucleation at a distance from the TPL (greater than $90^{\circ}$ ) and results in the ZB phase [103-105].

One of the major strategic challenge of the 21 st century still remains the integration of III-V devices with silicon, driven by the demand for data treatment and transmission. Transitioning from electrical data transmission to optical data communication is one of the key points that focus attention. Obviously, the NW geometry allows to evacuate the elastic stress due to the large lattice mismatch between the III-V materials and $\mathrm{Si}$ (ranging from 4 to $11 \%$ ) through the free lateral surfaces of the NWs. Nevertheless, nucleation and further growth of III-V materials on Si is not that easy. HVPE brings answers to issues encountered in MOVPE (nucleation issue) and in MBE (doping issue).

\section{Integration of GaAs NWs on silicon substrate}

\section{III.1 Introduction}

For Au-assisted VLS growth of GaAs NWs on GaAs substrates, MBE [106-108] and MOVPE [109,110] operate at temperatures ranging from 400 to $620^{\circ} \mathrm{C}$. HVPE GaAs NWs are grown at temperatures higher than $700{ }^{\circ} \mathrm{C}$. In this wide 
range of temperatures, the atomic interdiffusion between the substrate and the catalyst always serves as an additional supply of gallium and should be favorable for the NW nucleation on GaAs substrates [106,88].

The picture becomes different when the VLS growth of GaAs NWs takes place on silicon substrates covered or not with an oxide layer. Yet, integrating III-V compounds or NWs with silicon is of prime interest, for it opens the way to the development of photonic integrated circuits on $\mathrm{Si}$ for data treatment. Implementing Au-assisted VLS growth on $\mathrm{Si}$ in the HVPE environment brings new insights to nucleation and $\mathrm{Si}$ doping issues of GaAs NWs.

\section{III.2 Au-catalysed VLS-HVPE of GaAs NWs on Si: the nucleation issue}

Au-assisted VLS growth of GaAs NWs requires the deposition of an ultra-thin gold film on Si. The further density of the NWs on unpatterned substrate depends on the dewetting of the Au film on the silicon substrate surface. The control of this step is crucial to adjust the density and the diameter of the NWs during VLS growth. Several papers have reported the dewetting of $\mathrm{Au}$ on GaAs substrate [111]. As for Si substrate, whether covered with its native oxide layer or covered with a controlled dioxide film, the kinetics of Au droplets formation is strongly modified. We have first studied the dependence of the diameter and spatial distribution of the droplets on the surface of Si (111) substrates with respect to the thickness of the $\mathrm{Au}$ film and the temperature of the substrate during deposition and post-deposition annealing step.

$\mathrm{Au}$ films of thickness ranging from 0.2 to $2 \mathrm{~nm}$ were deposited at room temperature (RT) in an UHV system, on $\mathrm{Si}$ (111) substrates covered with their native oxide. The films were subsequently annealed at $600^{\circ} \mathrm{C}$ for 10 minutes in UHV. Figure 6 displays the scanning electron microscopy (SEM) images of the surfaces for four thicknesses of gold. The first point that stands out is the increase of the droplets size and the decrease of the droplets density with increasing the Au film thickness.

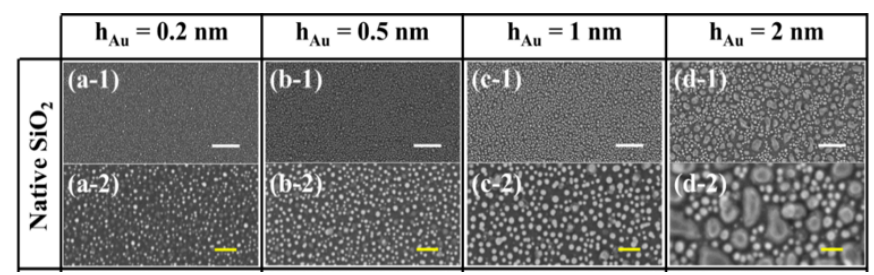

Figure 6. Distribution of Au droplets after deposition of (a1-a2) 0.2, (b1-b2) 0.5, (c1-c2) 1 and (d1-d2) $2 \mathrm{~nm}$ of $\mathrm{Au}$ on native $\mathrm{SiO}_{2}$ at RT followed by annealing at $600{ }^{\circ} \mathrm{C}$ for 10 minutes under UHV. The white and yellow scale bars represent $200 \mathrm{~nm}$ and $50 \mathrm{~nm}$, repectively [112].
The following main behaviours have been established supported by in-situ low energy electron microscopy (LEEM) coupled to low energy electron diffraction (LEED) technique [112]. When Au is deposited at RT, there is no effect of the oxide thickness on the size distribution and the density of the droplets. Under the annealing step in the range of $600^{\circ} \mathrm{C}$ $700^{\circ} \mathrm{C}$, and for thin $\mathrm{SiO}_{2}$ layers, the decomposition of the oxide is activated by the $\mathrm{Au}$ atoms. This process modifies the $\mathrm{Au}$ droplets growth. We have shown that large Au droplets decompose the $\mathrm{SiO}_{2}$ layer and unveil the $\mathrm{Si}$ (111) substrate while migrating perpendicular to the step edges. Small droplets are pinned and decay spontaneously. This study brings important information to NW growers using VPE methods. It allows to control the density and the diameters of the Au droplets for subsequent NW growth.

Contrary to MBE, in VPE methods, it is almost difficult to start growth of III-V materials on bare silicon surface. It is worth mentioning that the native $\mathrm{SiO}_{2}$ is always removed prior to the growth in MBE chambers. In the HVPE process, the $\mathrm{SiO}_{2}$ layer is always present at the surface of the substrate since HVPE operates at atmospheric pressure.

It has been shown that the presence of an oxide layer at the interface between gold and the silicon substrate blocks the inter-exchange between the two materials [113]. Therefore, the interdiffusion of $\mathrm{Si}$ atoms into the gold alloy droplets occurs only after decomposition of $\mathrm{SiO}_{2}$ underneath the droplets, which starts for temperatures above $400{ }^{\circ} \mathrm{C}$. The $\mathrm{Si}(\mathrm{s})$ $+\mathrm{SiO}_{2(\mathrm{~s})} \rightarrow 2 \mathrm{SiO}_{(\mathrm{g})}$ reaction is enhanced in the presence of gold atoms that reach the $\mathrm{SiO}_{2} / \mathrm{Si}$ interface by thermally activated diffusion into $\mathrm{SiO}_{2}$. Obviously, this diffusion is easier through thinner $\mathrm{SiO}_{2}$ layers. A similar enhancement is anticipated when the VLS growth on silicon is assisted by gallium droplets [102,114-116]. Additionally, the $\mathrm{SiO}_{2}$ layer can be decomposed at high enough temperatures via the reaction with gallium. A fraction of the gallium droplet is evaporated as $\mathrm{Ga}_{2} \mathrm{O}$ and the remaining part takes silicon atoms away from the substrate, leading to enhance silicon evaporation [117].

Therefore, in both gold-catalysed and self-assisted VLS growth of GaAs NWs on silicon substrates, the diffusion or readsorption of silicon atoms into the droplet prior to nucleation of GaAs NWs is unavoidable. The strength of this effect may vary depending on the deposition conditions and is anticipated to be larger for thinner oxide layers. Also, silicon should diffuse into the catalyst droplets more easily at higher temperatures and in chemical epitaxy techniques where different precursors are able to etch out silicon atoms from the substrate.

In order to quantify how the presence of $\mathrm{Si}$ atoms in the catalyst droplets affects the nucleation rate of GaAs NWs, V.G. Dubrovskii et al. developped a model, based on HVPE data [118]. This approach is general as it treats chemical potentials in a quaternary $\mathrm{Au}-\mathrm{III}-\mathrm{V}-\mathrm{Si}$ liquid alloy over a wide 
range of temperatures, and it is irrespective of a particular epitaxy technique employed. Therefore, any VLS growth of III-V NWs on silicon with different catalysts (gold, gallium, and indium) may be treated using the proposed scheme. Silicon is widely used as dopant for GaAs NWs. Here, we consider the influence of the silicon concentration in the droplet on the nucleation probability of pure GaAs NWs on different $\mathrm{SiOx} / \mathrm{Si}$ substrates, that is, not allowing for silicon to enter the solid state. The growth of Si-doped GaAs NWs and ultimately a ternary Si-GaAs solid alloy is presented in section III.3.

HVPE growth of GaAs NWs were performed after deposition of gold on native $\mathrm{SiO}_{2} / \mathrm{Si}$ (111) substrates (Figure 7 (a)) and on $\mathrm{Si}$ (111) substrates without native $\mathrm{SiO}_{2}$ (Figure 7 (b)). NWs grew easily when the native oxide was kept prior to the growth, while only few parasitic islands grew on the bare Si (111) after HF etching of the oxide layer. Matteini et al. reported the influence of surface silicon oxides on the density of self-catalyzed grown GaAs NWs [119]. In agreement with this work, we demonstrated that in VLS growth with Au-GaAs droplets, NW growth was enhanced as long as an oxide film is present on the substrate, which decreases the interdiffusion of Si atoms into the gold-alloy droplets [118]. Post-growth EDS quantitative analysis revealed that the silicon concentrations in the droplets were less than $2 \%$ on $\mathrm{SiO}_{2} / \mathrm{Si}$ (111) substrates and around $30 \%$ on bare $\mathrm{Si}(111)$ substrates. On the post-growth cooling stage under arsenic flux, Ga atoms were consumed, leading to droplet shrinking and the corresponding diminishing of the NW top radius. Assuming that the number of $\mathrm{Au}$ and $\mathrm{Si}$ atoms present in the droplet during growth remained the same after growth, we assessed the concentrations of $\mathrm{Si}$ and $\mathrm{Ga}$ atoms from geometry, by comparing the initial volume of the droplet with $\mathrm{Ga}$ and its final volume without $\mathrm{Ga}$, with the measured initial and final radii of the NW top [118]. In terms of Ga concentration, the calculations gave values close to 0.95 .

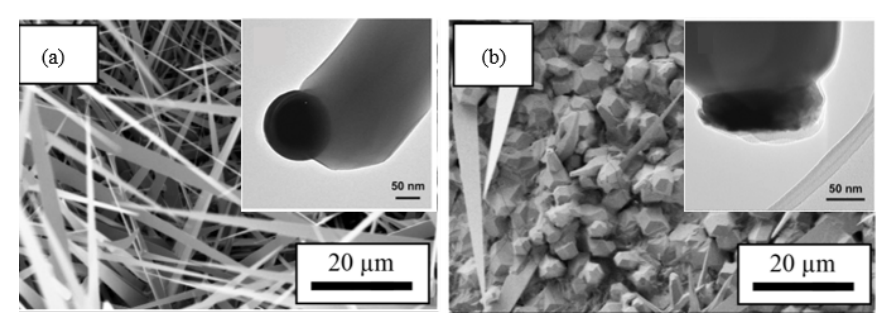

Figure 7. Scanning electron microscopy (SEM) images of the GaAs structures grown at $715^{\circ} \mathrm{C}$ after depositing $1 \mathrm{~nm}$ of gold on $\mathrm{Si}(111)$ (a) native $\mathrm{SiO}_{2}$ and (b) without $\mathrm{SiO}_{2}$. TEM images of the gold-catalysed GaAs structures with droplets on top, grown at $715^{\circ} \mathrm{C}$ [118].
A model based on the idea that adding silicon to the AuGa-As droplets had a drastic effect on chemical potentials, thus on the nucleation probability of GaAs NWs was developed. The model calls on a parameter $f$ that is written as the chemical potential difference per GaAs pair in the catalyst $\mathrm{Au}-\mathrm{Ga}-\mathrm{As}$ droplets with and without $\mathrm{Si}$ [118]. The variations of $\mathrm{f}$ as a function of the $\mathrm{Si}$ concentration $\left(\mathrm{c}_{\mathrm{Si}}\right)$ are plotted in Figure 8 for various concentrations of $\mathrm{Ga}\left(\mathrm{c}_{\mathrm{Ga}}\right)$ in the catalyst droplet. The curves are read like this: if $\mathrm{f}$ is negative, that is observed for Ga-rich droplets, then the chemical potentieal in the droplets containing $\mathrm{Si}$ is lower than the chemical potential in the droplets free of Si. It means that adding silicon to Garich gold-gallium droplets makes the initial nucleation of GaAs NWs more difficult. The condition $\mathrm{csi}_{\mathrm{Si}}<0.3$ at $\mathrm{c}_{\mathrm{Ga}}>0.65$ guarantees that the presence of silicon suppresses nucleation of GaAs NWs on Si(111). The limiting case of that is pure gallium-assisted growth $\left(\mathrm{c}_{\mathrm{Ga}}\right.$ close to 1$)$, which is the most sensitive to the presence of Si.

As a conclusion, $\mathrm{Si}$ suppresses nucleation from Ga-rich droplets as long as a certain critical concentration is not reached, with the most difficult nucleation for gold-free selfassisted VLS growth. As more Si atoms enter the droplets in MOVPE and HVPE due to enhanced silicon etching by the chemical precursors, we now explain the known issue of Gacatalysed growth of GaAs NWs by VPE techniques. Much less etching should be present during $\mathrm{MBE}$, so the silicon concentration is lower in the catalyst droplets and Gacatalysed GaAs NWs can easily be grown on Si by MBE $[114,115]$. The model confirms that having more gold in the droplets helps to nucleate GaAs NWs on silicon. This property has been long known for MOVPE (see, for example ref. [120, 121]).

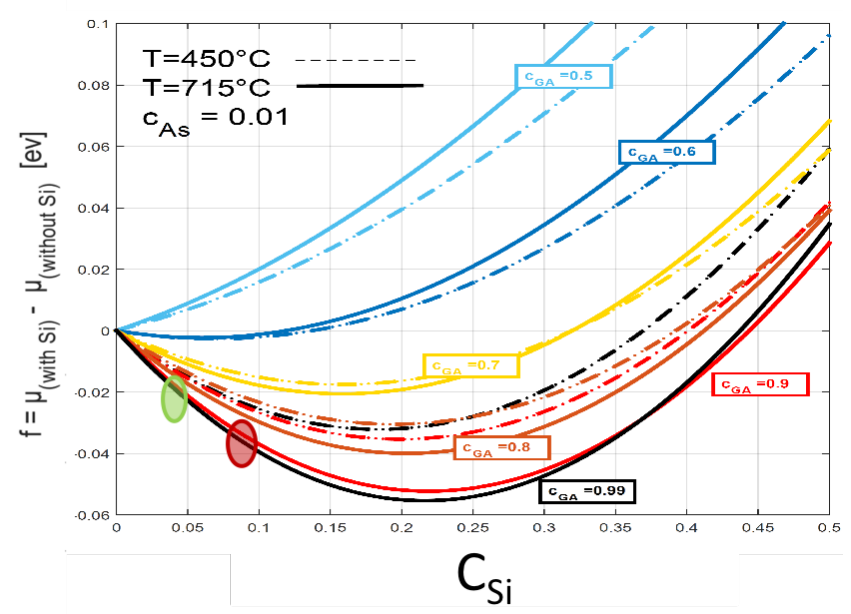

Figure 8. Chemical potential difference per Ga-As pair in Au-Ga-AsSi versus Au-Ga-As liquid droplets as a function of the Si concentration

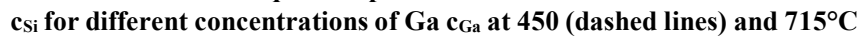
(solid lines). The As concentration was fixed at 0.01 [118]. 


\section{III.3 Au-catalysed VLS growth of GaAs:Si NWs on Si: the doping issue}

GaAs:Si NWS were grown on Si (111) substrates covered with a native $\mathrm{SiO}_{2}$ layer after deposition and annealing under UHV of a gold layer $1 \mathrm{~nm}$-thick, using $\mathrm{SiH}_{4}$ gas for doping. Various growth temperatures were tested [122].

From Figure 9, it comes out that the substrates contain high density of nanostructures. They exhibit large tapering at the base, except the ones grown at $580{ }^{\circ} \mathrm{C}$ (panel a) which have larger uniform diameters. The samples grown at $715^{\circ} \mathrm{C}$ present the thinnest structures. HRTEM and FFT revealed pure ZB phase of representative NWs [122]. Microphotoluminescence was performed on GaAs NWs with different Si doping concentrations. The blueshift of the spectra revealed the n-type behavior of GaAs NWs grown by HVPE.

$\mathrm{Si}$ is known for amphoteric behavior [123-126]. Replacing $\mathrm{Ga}$ with $\mathrm{Si}$ atoms creates As-Si pairs and results in n-type doping, while replacing As with Si atoms creates Ga-Si pairs and results in p-type doping. The replaced Ga or As atoms are dissolved in the liquid droplet. This property has previously been used to change the doping of GaAs layers from $n$-type to p-type in MBE by tuning the growth conditions. In the case of MBE, p-doping is achieved by lowering the As/Ga ratio and increasing the growth temperature [127]. V.G. Dubrovskii developed a model to understand why Si can act as a n-type or p-type dopant in GaAs NWs grown by VLS, while it remains a n-type dopant of GaAs grown by vapor-solid (VS) condensation [122].

Considering the VLS growth of GaAs:Si NWs from a quaternary $\mathrm{Au}-\mathrm{Ga}-\mathrm{As}-\mathrm{Si}$ liquid alloy, we study the $\mathrm{Si}$ incorporation from liquid to solid under equilibrium conditions for all species containing Si (Figure 10). Such an approach has recently been justified for the compositional modeling of ternary III-V NWs [128] and is expected to be even more relevant for doping due to extremely low $\mathrm{Si}$ concentrations in both liquid and solid phases.

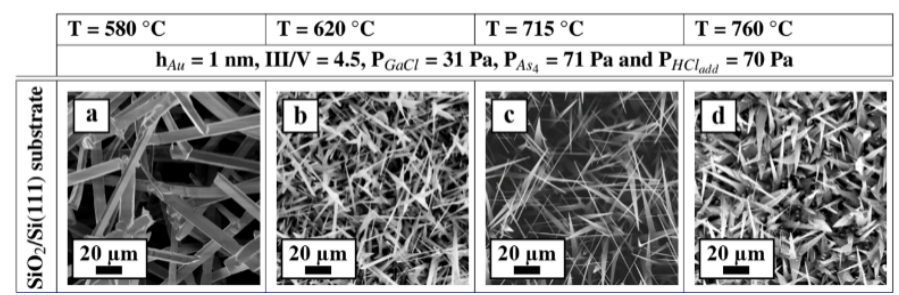

Figure 9. SEM images showing the grown HVPE nanostructures at different temperatures on gold native $\mathrm{SiO}_{2} / \mathrm{Si}(111)$ substrate. Growth time was 30 min.

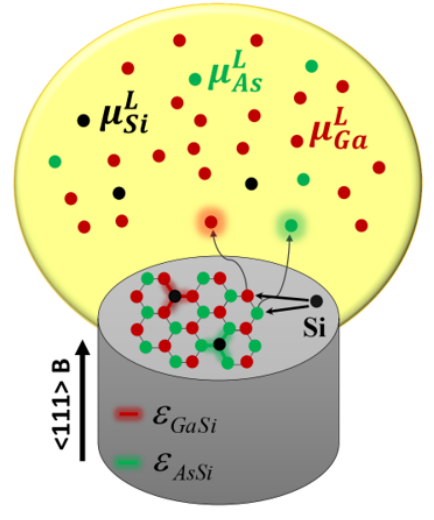

Figure 10. Illustration of the VLS growth of $<111>$ B-oriented zincblende GaAs NWs with Si. Si can be incorporated into either Ga or As sites of GaAs. Replacing Ga with a $\mathrm{Si}$ atom (n-type doping) creates AsSi pair with a contribution $\varepsilon_{\mathrm{AsSi}}$ to the total internal energy and increases the chemical potential $\mu_{G a}^{L}$ by adding one Ga atom to the liquid. Replacing As with a Si atom (p-type doping) creates Ga-Si pair with a contribution $\varepsilon_{\mathrm{GaSi}}$ to the total internal energy and increases the chemical potential $\mu_{A s}^{L}$ by adding one As atom to the liquid [122].

The atom fractions of Si replacing Ga and As in solid GaAs, respectively $\mathrm{x}$ and $\mathrm{y}$, are written as a function of chemical potentials:

$$
\begin{aligned}
& \mathrm{x}=\exp \left(\frac{\mu_{\mathrm{GaAs}}^{\mathrm{P}}-\mu_{\mathrm{AsSi}}^{\mathrm{P}}+\mu_{\mathrm{Si}}^{\mathrm{L}}-\mu_{\mathrm{Ga}}^{\mathrm{L}}+\Delta \mu_{\mathrm{GaAs}}}{\mathrm{k}_{\mathrm{B}} \mathrm{T}}\right) \\
& \mathrm{y}=\exp \left(\frac{\mu_{\mathrm{GaAs}}^{\mathrm{P}}-\mu_{\mathrm{GaSi}}^{\mathrm{P}}+\mu_{\mathrm{Si}}^{\mathrm{L}}-\mu_{\mathrm{As}}^{\mathrm{L}}+\Delta \mu_{\mathrm{GaAs}}}{\mathrm{k}_{\mathrm{B}} \mathrm{T}}\right)
\end{aligned}
$$

where $\mathrm{k}_{\mathrm{B}}$ is the Boltzmann constant, chemical potential $\mu_{\mathrm{i}}^{\mathrm{P}}$ corresponds to the reference solid state of pure species $i, \mu_{i}^{L}$ is the chemical potential of liquid species $i$. $\Delta \mu_{\mathrm{GaAs}}=\mu_{\mathrm{Ga}}^{\mathrm{L}}+\mu_{\mathrm{As}}^{\mathrm{L}}-\mu_{\mathrm{GaAs}}^{\mathrm{P}}$ is the difference of chemical potentials per GaAs pair in the liquid and solid phases.

Figure 11 shows the variation of the $\mathrm{x} / \mathrm{y}$ ratio as a function of the $\mathrm{Ga}$ concentration $\mathrm{c}_{\mathrm{Ga}}$ in the catalyst Au-Ga-As-Si droplet, for two different growth temperatures $\mathrm{T}$ and for various As concentrations in the droplet. The curves cover the growth conditions for both MBE [108] and HVPE VLS growth of GaAs NWs. The details of the theoretical computing of the $\mathrm{x} / \mathrm{y}$ ratio performed by density functional theory (DFT) are given in ref. [122].

Figures 11 clearly reveals the following trends: (i) Increasing the As concentration in the catalyst droplet always favors n-type doping; (ii) At a fixed As concentration, increasing the Ga content in the droplet favors n-type doping; therefore, n-type GaAs:Si NWs should be more easily obtained in Au-catalysed growth with Ga-rich droplets; (iii) ntype doping becomes more likely for lower substrate temperatures. 


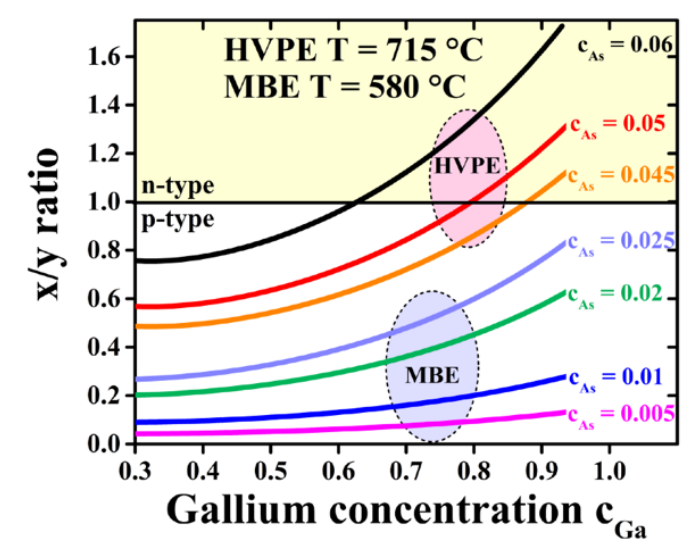

Figure 11. (a) The ratio $x / y$ versus $G a$ concentration in catalyst droplet under the typical $\mathrm{MBE}\left(580^{\circ} \mathrm{C}\right.$, low As concentrations $\left.<0.025\right)$ and HVPE $\left(715^{\circ} \mathrm{C}\right.$, high As concentrations $\left.>0.045\right)$ growth conditions for Au-catalysed GaAs NWs. The zero doping line (for $x=y$ ), corresponds to a ratio of 1 . The yellow region above the line corresponds to n-type doping and the white region below the line corresponds to p-type doping. The following trends can be seen: (i) MBE-grown GaAs:Si NWs are always p-type; (ii) In the case of HVPE, GaAs:Si NWs are p-type at lower As and Ga concentrations and n-type at higher $A s$ and $G a$ concentrations; (iii) All HVPE-grown NWs become n-type for $c_{G a}>0.87$ [122].

In conclusion, it has been shown that $\mathrm{Si}$ atoms are preferentially incorporated into As, rather than Ga sites of GaAs NWs, due to a much lower As/Ga ratio in the mother phase during the VLS growth compared to VS growth. This explains why most VLS GaAs:Si NWs are p-type, while the standard VS growth leads to n-type doping. However, n-type doping of GaAs NWs with $\mathrm{Si}$ is expected at higher As concentrations in the droplet, which occurs for HVPE growth on Si substrates. These results can be used for obtaining n-type or p-type Si doping in GaAs NWs by tuning the growth conditions, or even Si-doped $\mathrm{p}$-n junctions within a single NW.

\section{Self-catalysed growth of GaAs and InAs NWs on silicon substrate}

\section{IV.1 Thermodynamic conditions to form Ga and In liquid droplets from chloride gaseous molecules}

In order to grow self-catalysed III-As NWs, a thermodynamic analysis of the conditions that yield the deposition of liquid droplets of Ga or In in HVPE has to be investigated. Gallium or indium droplets should nucleate from III-Cl gaseous molecules. One should consider the chemical reactions involving any $\mathrm{III-Cl}$ ng species likely to be present in the vapor phase to form liquid droplets of element III on the substrate surface:

$$
\mathrm{IIICl}_{\mathrm{ng}}+\frac{\mathrm{n}}{2} \mathrm{H}_{2 \mathrm{~g}} \leftrightarrows \mathrm{III}+\mathrm{nHCl}_{\mathrm{g}}
$$

For instance, $\mathrm{GaCl}_{2 \mathrm{~g}}$ and $\mathrm{GaCl}_{3 \mathrm{~g}}$ molecules are found in the vapor phase at a temperature of $600^{\circ} \mathrm{C}$, and all the more for higher temperature, provided the $\mathrm{Cl} / \mathrm{H}$ atomic ratio is low, which is always the case for HVPE carried out at atmospheric pressure under $\mathrm{H}_{2}$ vector gas [129].

The equilibrium constants $\mathrm{K}$ for the reactions producing liquid $\mathrm{Ga}$ or liquid In and $\mathrm{HCl}_{\mathrm{g}}$, from $\mathrm{GaCl}_{\mathrm{g}}$ or $\mathrm{InCl}_{\mathrm{g}}$ and $\mathrm{H}_{2 \mathrm{~g}}$ reactants were calculated using thermochemical data of ref. [130]. They are plotted in Figure 12 as a function of temperature $\mathrm{T}$. Both equilibrium constants $\mathrm{K}_{\mathrm{Ga}}$ and $\mathrm{K}_{\mathrm{In}}$ rapidly decrease with increasing temperature and are much smaller than 1 for the usual process temperature in $\operatorname{HVPE}\left(\mathrm{T}>600^{\circ} \mathrm{C}\right)$, indicating that the material balance at equilibium is not in favor of liquid gallium or indium when trying to form droplets from III-Cl gaseous molecules. As a matter of fact, any attempt to form droplets on a $\mathrm{Si}$ surface from III-Cl gaseous species is doomed to failure. As a consequence, the stabilization of droplets of $\mathrm{Ga}$ or In requires the presence of both III and As species. Gaseous III-Cl and As precursors are to be supplied simultaneously at $600^{\circ} \mathrm{C}$. In order to prevent the two-dimensional crystallization of GaAs or InAs that would lead to the fast consumption of the droplets, the ratio of the III-Cl to the As input partial pressures should be tremendously high, to drive the supersaturation toward nucleation of liquid $\mathrm{Ga}$ or In on the substrate surface. As a conclusion, unusual III/V atomic flow ratios are necessary to keep the Ga or Indroplets that will subsequently catalyze the VLS nucleation and growth of III-V NWs in a HVPE reactor.

\section{IV.2 Self-catalysed growth of GaAs NWs on Si}

Gold-free growth techniques such as VLS catalysed by the group III metal rather than gold, are developed to save one step before growth and facilitate the integration of III-V devices with the silicon platform. Ga-catalysed VLS growth of GaAs NWs by MBE was introduced by Colombo et al. [131]. Since then, remarkable progress has been achieved towards MBE synthesis, theoretical understanding and tailoring of physical properties, and device implementation of such NWs [119,132-134]. In particular, one can take advantage of well-developed techniques of $\mathrm{SiO}_{\mathrm{x}} / \mathrm{Si}$ preparation and processing that influence the NW morphology to obtain high crystal phase purity (ZB) and modulate the NW diameter by tuning the As/Ga flux ratio [91,133,135].

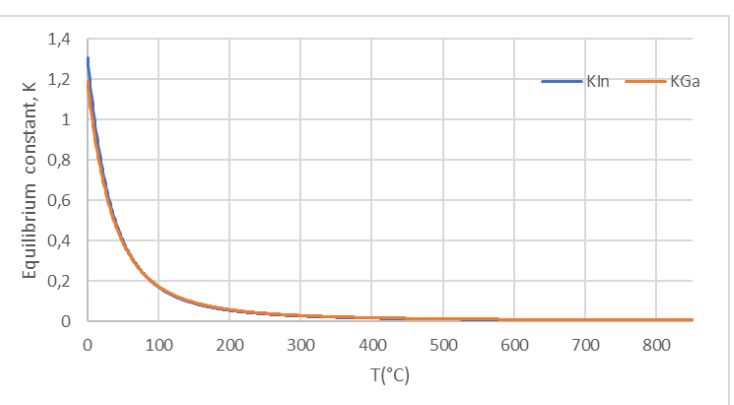

Figure 12. Temperature dependence of the equilibrium constants $K_{\mathrm{Ga}}$ and $\mathrm{K}_{\mathrm{In}}$ for dechlorination of $\mathrm{GaCl}$ and $\mathrm{InCl}$ gaseous precursors into liquid Ga and In. Thermodynamic calculations show the preferred material balance for gaseous $\mathrm{GaCl}$ and $\mathrm{InCl}$ rather than liquid $\mathrm{Ga}$ and In ( $\mathrm{K}$ are lower than 1 for temperatures as low as $20^{\circ} \mathrm{C}$ ). 
Furthermore, gallium droplets can self-equilibrate to a certain stationary size within a range of As/Ga flux ratios and this effect leads to a narrowing of the radius distribution of NWs [102,115,136]. The elongation rate of Ga-catalysed GaAs NWs is determined by the arsenic vapor flux and is radius-independent for sufficiently large droplets [102,131], which improves the length uniformity within the NW ensembles [31]. All these features allow for MBE growth of GaAs NWs on silicon with the highest crystal quality, spatial uniformity and tunable morphology.

Ga-catalysed VPE growth of GaAs NWs, namely by the metal-organic VPE technique, remains a very challenging task and does not produce structures with morphological and crystal phase perfections comparable to those obtained by MBE. The main problem is due to the high temperature (at least $600^{\circ} \mathrm{C}$ ) required for cracking organo-gallium precursors combined with arsenic-rich atmosphere in the reactor. Such conditions do not favor both initial nucleation and further stability of liquid gallium droplets [137]. Given these limitations, it is extremely difficult to find appropriate conditions for Ga-catalysed VLS growth, and the NWs obtained so far are limited in length (typically less than $1 \mu \mathrm{m}$ ).

First Ga-catalysed VLS growth of GaAs NWs by HVPE was carried out on partially etched native $\mathrm{SiO}_{2} / \mathrm{Si}$ (111) substrate, at $600^{\circ} \mathrm{C}$. Hexagon bottle-like GaAs NWs, 2 to 10 $\mu \mathrm{m}$-long, were grown in a $10 \mathrm{~min}$-step. The density of NWs was very low (see Figure $13(\mathrm{~g})$ ) [138]. This low density is related to the lack of liquid Ga droplets on the surface (see section IV.1). Actually, the oxide thickness has a lower influence in HVPE than in MBE. In order to increase the NWs density, one should deposit ex-situ Ga droplets and further keep the substrate under controlled atmosphere to prevent the oxidation of the droplets.

HRTEM images of typical GaAs NWs mechanically separated from the substrate and deposited on a holey carbon grid are shown in Figure 13. The NW shown in Figures 13 (a) to (f) grown at $600{ }^{\circ} \mathrm{C}$ presents a very thick (300 nm at the base) tapered trunk with a pure ZB crystal structure (Figure 13 (b)) and no evidence of twins or stacking disorder as often observed in MBE-grown self-catalysed GaAs NWs [91]. A similar NW observed perpendicular to the growth axis reveals a base of hexagonal shape (Figure 13 (f)). Elemental maps of Ga and As obtained from EDS analysis show that the NW has a homogeneous composition of gallium and arsenic (Figures 13 (d) and 13 (e)), and in particular no Ga droplets or Ga-rich regions are found at the NW tip. As a matter of fact, all the excess gallium should be completely consumed in the cooldown stage under $\mathrm{As}_{2} / \mathrm{As}_{4}$ atmosphere. So we assume that the NWs were grown by Ga-catalyzed VLS growth, according to four steps described in the discussion below.

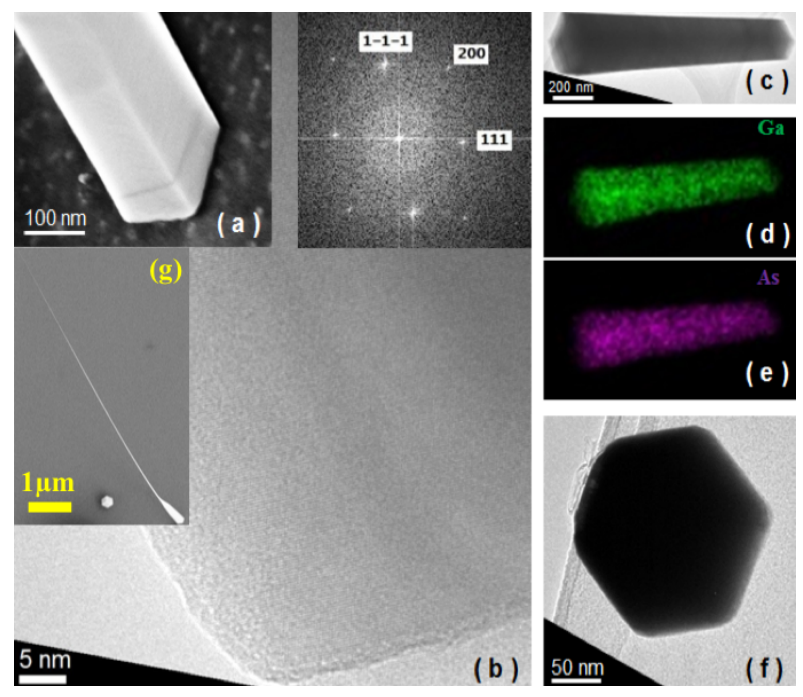

Figure 13. GaAs NW grown at $600^{\circ} \mathrm{C}$ with $\mathrm{III} / \mathrm{V}=55$. (a) Contact part of GaAs NWs and $\mathrm{Si}(111)$. (b) Corresponding HRTEM image of the bottom part, the FFT above reveals the defect free cubic $\mathrm{ZB}$ structure of the NW. (c) TEM image of a GaAs NW with a thick trunk (base dimension=300 $\mathrm{nm}$ ). (d), (e) Corresponding gallium and arsenic elemental maps from EDS. (f) TEM image of a NW view along the growth axis evidencing the hexagonal shape of the base. (g) SEM image of one typical GaAs NW, showing the particular bottle shape [138].

All NWs are oriented along the $<111>$ B direction. NWs have different lengths on a single sample. The average integrated growth rate (i.e., the mean NW length divided by the total growth time of $10 \mathrm{~min}$ ) can be estimated to $30 \mu \mathrm{m} / \mathrm{h}$. Figure 14 (a) displays the variation of the mean NW length as a function of the arsenic partial pressure at a fixed $\mathrm{GaCl}$ partial pressure: the NW length decreases with increasing the As partial pressure until complete supression of the NW growth. This behavior is unusual compared with MBE, where the axial NW growth rate increases with the arsenic flux [91,133,139]. Figure 14 (b) shows the non-monotonic dependence of the mean NW length with increasing the $\mathrm{GaCl}$ partial pressure [129]. In the case of MBE, the axial NW growth rate is not influenced by the gallium flux that only changes the droplet size [91,139]. Indeed, Ga-catalysed VLS-HVPE involves four steps. To explain the low density of NWs, one should work on the very first step which is the nucleation step. V.G. Dubrovskii demonstrated that initial nucleation requires that the surface coverage in Ga atoms reaches locally a critical value, upon vapor flux and surface diffusion after adsorption on the substrate [138]. We showed in section IV.1 that it was particularly difficult to get liquid Ga adsorbed on the substrate surface from gaseous $\mathrm{GaCl}$ molecules. As a result, very few NWs can be grown. Second step is the inflation of the droplet which is rapid once the seed was nucleated. The third step is the shrinking of the droplet because of a high input flux of As, followed by a stationary regime (step 4) once the balance between the Ga flux and the As flux is reached. The four steps were modelled as a function of the adsorption flux of $\mathrm{Ga}$, the 

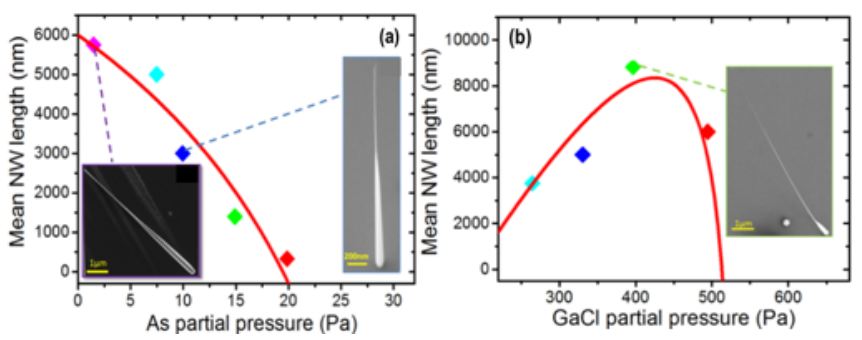

Figure 14. (a) Variation of the mean GaAs NW length as a function of (a) the As partial pressure at a fixed $\mathrm{GaCl}$ partial pressure of $330 \mathrm{~Pa}$, (b) the $\mathrm{GaCl}$ partial pressure at a fixed As partial pressure of $7.5 \mathrm{~Pa}$. (b) Growth temperature was $600^{\circ} \mathrm{C}$. All SEM images show corresponding GaAs NWs [138].

net adsorption flux of As as we consider the possible desorption of the As element, and geometrical parameters related to the droplet (radius, height, contact angle) [138].

These results, namely very low density and bottle-like shape NWs, clearly demonstrate that HVPE is not suitable for self-catalysed growth of GaAs NWs on non patterned substrates. One should look to direct condensation of the III$\mathrm{V}$ on $\mathrm{Si}$, as initiated with InAs.

\section{IV.3 Growth of InAs NWs on Si}

InAs has a direct and narrow band gap, high electron mobility and small electron effective mass. The integration of InAs with $\mathrm{Si}$ is of great interest for ultra-high speed and lowpower components [140]. The planar heteroepitaxy of high quality InAs materials on $\mathrm{Si}$ is even more difficult than it is for GaAs due to the larger difference in the lattice constants between InAs and $\mathrm{Si}$ (11.4\%). Lapierre et al. have demonstrated the high potential of MBE to grow InAs NWs with a special focus on infrared detectors applications [141143]. Yet, while indium-catalysed VLS growth of InAs NWs have been successfully demonstrated by both MBE and MOVPE, to our knowledge no demonstration of InAs NWs growth was given by HVPE.

In self-catalyzed MBE, the indium catalyst is obtained either by in-situ deposition prior to growth [144] or by initiating growth under indium rich conditions [145]. The NW morphology is very sensitive to the growth parameters such as the temperature and the vapor phase composition. For instance, if highly arsenic rich conditions are used, growth leads to InAs NWs with a highly defective wurtzite structure [146]. Nevertheless, InAs-based NW heterostructures have been successfully demonstrated by MBE [145,147].

Dick et al. investigated self-catalyzed MOVPE growth in the range of [400-500] $]^{\circ} \mathrm{C}$ on InAs and InP substrates [148]. The same group was pioneer in the growth of InAs NWs on silicon substrates [149]. Recent MOVPE work involved $\mathrm{Si}$ wafers precoated by metallic masks, to avoid the use of gold catalyst and reduce process costs [150]. Light emitting InAs
NWs were grown directly on flexible plastic substrates by Inseeded MOVPE [151].

In MBE and CBE, several groups showed that vapor-solid (VS) growth of InAs NWs was mainly limited by the surface diffusion of adatoms, which does not favor a pure crystalline quality of NWs that exhibit a high density of twin planes, stacking faults and alternating $\mathrm{ZB} / \mathrm{WZ}$ segments along the growth axis [144,145,152]. MOVPE provided also very promising results in the case of SAG, even though the wires did not exhibit a pure crystalline quality all along the NWs length limited to few microns $[153,154]$.

As a conclusion, when InAs NWs are grown by selfassisted VLS or VS epitaxy, their structural quality is clearly inferior to that of NWs grown by Au-assisted VLS epitaxy. It is highly relevant to develop a better understanding of the emergence of polytypism in NWs and to grow defect free NWs. The question is what the contribution of HVPE with its specific thermodynamic and kinetic properties would be in this context.

As described in section IV.1, the material balance at equilibrium is not in favor of the formation of liquid indium droplet in the growth temperature range $\left(580^{\circ} \mathrm{C}-720^{\circ} \mathrm{C}\right)$ for InAs. Thus HVPE growth of InAs should proceed by condensation. Figure 15 (a) displays the SEM image of InAs NWs grown on $\mathrm{Si}(111)$ at $640^{\circ} \mathrm{C}$. In this work, no surface treatment has been done prior to growth, except HF etching of silicon substrates prior to their introduction into the reactor. Consequently, the NWs were grown on silicon surfaces presenting random re-oxidation and random holes in the native silicon oxide. The NWs were grown predominantly along the vertical $<111>$ B direction whatever the growth temperature. Very few tilted NWs were observed. We attribute the existence of the two populations to the non-polar nature of the $\mathrm{Si}$ (111) substrate. It is clearly seen that the NWs exhibit a hexagonal shape delimited by six equivalent $\{1 \overline{1} 1\}$ side facets and the (111)B facet at the top.
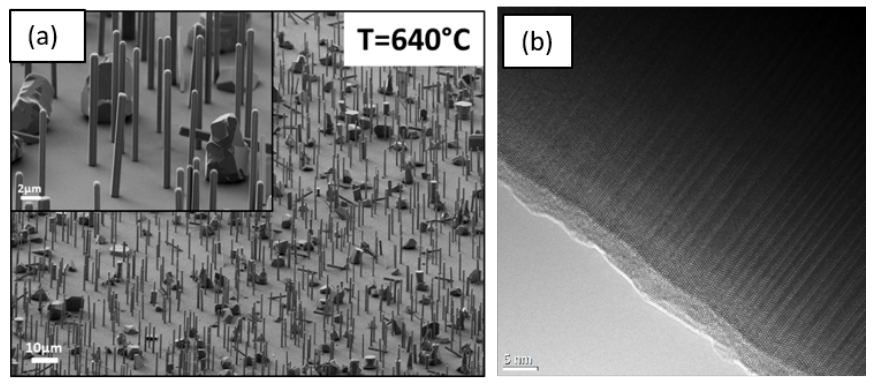

Figure 15. (a) SEM images of InAs NWs grown on Si (111) substrate at $640{ }^{\circ} \mathrm{C}$. (b) HRTEM of a single InAs NW showing alternate stacking of zinc blende (ZB) crystalline structures with inclusions of wurtzite $(\mathrm{WZ})$ and twin planes. 
Alternate stacking of ZB segments with inclusions of WZ and twin planes are visible in Figure 15 (b). These observations have been confirmed whatever the HVPE growth conditions of temperature and III/V ratio. In $\mathrm{MBE}$, it is assumed that the appearance of such structural defects is linked to the surface reconstruction of the (111)B face [154], during InAs growth implemented under As-rich conditions. With partial pressures of As4 ranging from 3,5 x 10-4 atm (35 $\mathrm{Pa})$ to $1 \times 10^{-3} \mathrm{~atm}(101 \mathrm{~Pa})$, it is obvious that HVPE falls into such a regime.

The average axial growth rate of the InAs NWs is plotted as a function of the growth temperature $\mathrm{T}$ in Figure 16. It ranges from some $\mu \mathrm{m} / \mathrm{h}$ to more than $50 \mu \mathrm{m} / \mathrm{h}$ and exhibits a bell curve as a function of $\mathrm{T}$. This strong dependence with the temperature demonstrates that growth is governed by the surface kinetics and the thermally-activated steps, as described in section I. Alike planar growth, NW axial growth is limited by inihibited dechlorination of $\mathrm{AsInCl}$ ad-species at low $\mathrm{T}$ and normal lack of material adsorption at high $\mathrm{T}$. Having demonstrated the potential of HVPE for the easy nucleation and condensation growth of InAs NWs on unprepared and unpatterned Si substrate, efforts are now made to lower the As partial pressure to get pure phase InAs NWs. Selective area growth on patterned $\mathrm{Si}$ substrates is also ongoing to fabricate regular and periodic arrays of InAs NWs of which length can be tuned at will by HVPE in short process time.

\section{Summary}

GaAs NWs grown by Au catalyst-assisted VLS-HVPE on GaAs (001) feature an untapered morphology with a constant diameter. They show very high aspect ratio, ranging from 800 to 1000 for radii ranging from 50 to $130 \mathrm{~nm}$. They are grown at a high axial growth rate greater than $100 \mu \mathrm{m} / \mathrm{h}$. GaAs NWs exhibit defect-free and stacking fault-free zinc blende structure. The occurrence of polytypism-free ZB phase in Aucatalysed GaAs NWs of record radii lower than $15 \mathrm{~nm}$ down to $5 \mathrm{~nm}$ was demonstrated for the first time. Theoretical modeling was proposed to elucidate the unexpected $\mathrm{ZB}$ structure and its purity for such small dimensions.

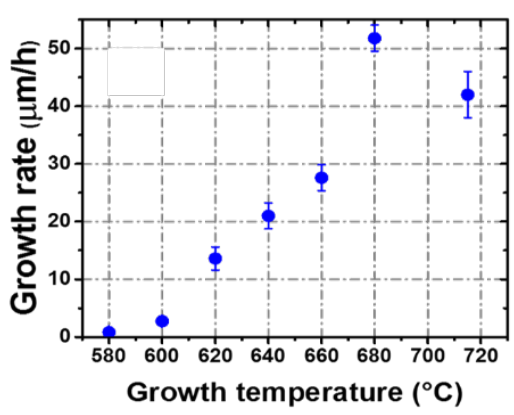

Figure 16. Average axial growth rate of InAs NWs grown by HVPE as a function of the growth temperature.
Nanowire growth by VLS-HVPE only proceeds by introduction of precursors in the catalyst droplets from the vapor phase. This promotes almost pure axial growth leading to NWs with a constant cylinder shape over unusual length. We demonstrate that VLS-HVPE takes place at high liquid chemical potential that originates from very high influxes of both As and Ga. The high Ga concentration in the Au-Ga-As droplets decreases the surface energy of the droplets, which disables nucleation at the triple phase line thus preventing the formation of WZ structure regardless of the NW radius. This conclusion supported theoretical and experimental data obtained by MBE, where it was demonstrated that high Ga concentration was needed to yield $\mathrm{ZB}$ nucleation for $\mathrm{Au}-$ assisted VLS-MBE, and that one should switch to Ga-catalyst to guarantee pure ZB GaAs NWs.

The implementation of Au-assisted VLS-HVPE on Si (111) revealed very interesting nucleation property and solved the enigma related to the almost impossible VLS growth of GaAs NWs on Si by VPE methods. It was demonstrated that the presence of silicon in Au-Ga-As droplets suppresses nucleation as long as a certain critical Ga concentration is not reached. We speculate that more silicon atoms enter the droplets in MOVPE and HVPE due to enhanced silicon etching by chemical precursors, thus inhibiting nucleation of NWs.

Si atoms play another big role as being doping element for GaAs. Si-doped GaAs NWs were grown by Au-assisted VLSHVPE and a model for Si doping was developed. Si atoms are preferentially incorporated into As rather than Ga sites, because of a much lower As/Ga ratio prevailing in the mother phase during VLS growth compared to VS growth. This explains why most VLS Si-doped GaAs NWs are p-type, whereas the standard planar VS growth leads to n-type doping. n-type doping of GaAs NWs with $\mathrm{Si}$ is expected at higher As concentrations in the droplet, which occurs for VLS-HVPE growth on $\mathrm{Si}$ substrates. These results can be used for obtaining n-type or p-type Si doping in GaAs NWs by tuning the growth conditions, or even Si-doped p-n junctions within a single NW.

The development of low cost gold-free growth protocols by VPE techniques still remains an issue. Defect-free GaAs NWs were successfully grown by Ga-assisted VLS-HVPE on Si (111) substrates. However, as it is also observed in MOVPE, the NW density was drastically low. Actually, metal droplets can hardly be formed and stabilised from chloride gaseous precursors at temperature involved in HVPE. The presence of Si atoms in the droplets also hinders NW nucleation as already discussed, which affects both HVPE and MOVPE processes.

For InAs NWs, the HVPE environment is more favorable. Recently and for the first time, direct growth of vertically aligned InAs NWs on silicon substrate was demonstrated by HVPE. The NWs grow along the $<111>\mathrm{B}$ direction with a 
constant diameter. The growth occurs through pure VS condensation. It is mainly governed by the surface kinetics of adsorption, desorption and decomposition (dechlorination) of adsorbed species. However, the NWs still exhibit polytypism. Further work is in progress to improve the crystalline quality of the NWs versus the growth conditions.

HVPE is the third epitaxial technique to be used for the synthesis of NW arrays either by VLS, VS or selective area growth on patterned substrates. Because HVPE operates at conditions of temperature and vapor phase composition different from those of MBE and MOVPE, HVPE experimental results helped in solving issues encountered by MBE and MOVPE, and strengthened assertions upon growth and nucleation mechanisms. The low cost HVPE technique is now engaged along with MBE and MOVPE in the monolithic integration of arrays of III-V NWs directly with silicon. HVPE is indeed complementary to MBE and MOVPE, and pave the way for applications in optoelectronics, electronics and sensor development, especially where long NWs are needed.

\section{Acknowledgements}

This work has been supported financially by the CPER MMASYF of Région Auvergne-Rône Alpes that we acknowledge gratefully. It was also funded by the program "Investissements d'avenir" of the French ANR agency, the French governement IDEX-SITE initiative 16- $\mu$ IDEX-0001 (CAP20-25), the European Commission (Auvergne FEDER Funds) and the Region Auvergne in the framework of the LabEx IMobS3 (ANR-10-LABX-16-01) and CPER. This work was supported by the Russian Science Foundation under the Grant 19-72-30004. This work was supported by Région Auvergne Rhône-Alpes Pack Ambition Recherche; Convention $n^{\circ} 17011236$ 01-61617.

The authors thank 2MAtech, Aubiere, France, for scanning electron microscopy measurements. Also, Electron microscopy was performed at the Canadian Centre for Electron Microscopy (also supported by NSERC and other government agencies).

\section{References}

[1] Ainslie NG 1962 J. Appl. Phys. 332391

[2] Hollan L and Schiller C 1972 J. Cryst. Growth 13/14 319

[3] Hollan L 1980 Current topics in materials science 5 ed. E. Kaldis 1

[4] Wolff G 1954 Phys. Rev. 94753

[5] Rosi FD 1959 J. Phys. Chem. Sol. 8498

[6] Nelson H 1963 RCA Rev. 24603

[7] Sun Y, Khang Y, Hua F, Hurley K, Nuzzo RG and Rogers, JA 2005 Adv. Func. Mater. 1530

[8] Song Y, Li X, Kim SH, Ishihara T and Mohseni PK 2015 Nano Lett. 15641

[9] Wagner RS and Ellis WC 1964 Appl. Phys. Lett. 489

[10]Hiruma K, Katsuyama T, Ogawa K, Koguchi M, Kakibayashi H and Morgan GP 1991 Appl. Phys. Lett. 59431
[11]Heiss M, Fontana Y, Gustafsson A, Wuest G, Magen C, O'Regan DD, Luo JW, Ketterer B, Conesa-Boj S, Kuhlmann AV, Houel J, Russo-Averchi E, Morante JR, Cantoni M, Marzari N, Arbiol J, Zunger A, Warburton RJ and Fontcuberta i Morral A 2013 Nature Materials 12439

[12] Heurlin M, Magnusson MH, Lindgren D, Ek M, Wallenber, LR, Deppert K and Samuelson L 2012 Nature 49290

[13]Mariani G, Zhou ZL, Scofield AC and Huffaker DL 2013 Nano Lett. 41632

[14]Bolshakov AD, Fedorov VV, Sibirev NV, Fetisova MV, Moiseev EI, Kryzhanovskaya NV, Koval OY, Ubyivovk EV, Mozharov AM, Cirlin GE and Mukhin IS 2019 Phys. Status Solidi 131900350

[15]Bolshakov AD, Dvoretckaia LN, Fedorov VV, Sapunov GA, Mozharov AM, Shugurov KY, Shkoldin A, Mukhin MS, Cirlin GE and Mukhin IS 2018 Semiconductors 522088

[16]Xia Y, Yang P, Sun Y, Wu Y, Mayers B, Gates B, Yin Y, Kim $\mathrm{F}$ and Yan H 2003 Adv. Mater. 15353

[17]Law M, Goldberger J and Yang P 2004 Annu. Rev. Mater. Res. 3483

[18]Kolasinski KW 2006 Curr. Opin. Solid State Mater. Sci. 10182 [19] Thelander C, Agarwal P, Brongersma S, Eymery J, Feiner L, Forchel A, Scheffler M, Riess W, Ohlsson B, Gösele U and Samuelson L 2006 Mater. Today 928

[20]Sun J, Han M, Gu Y, Yang Z and Zeng H 2018 Adv. Opt. Mater. 61800256

[21]Rurali R 2010 Rev. Mod. Phys. 82427

[22]Ross FM 2010 Rep. Prog. Phys. 73114501

[23]Dick KA, Caroff P, Bolinsson J, Messing ME, Johansson J,

Deppert K, Wallenberg LR and Samuelson L 2010 Semicond. Sci.

Technol. 25024009

[24]Lieber CM 2011 MRS Bull. 361063

[25] Johansson J and Dick KA 2011 CrystEngComm 137175

[26] Garnett EC, Brongersma ML, Cui Y and McGehee MD 2011

Annu. Rev. Mater. Res. 41269

[27]Hobbs RG, Petkov N and Holmes JD 2012 Chem. Mater. 24 1975

[28]Natarajan CM, Tanner MG and Hadfield RH 2012 Supercond. Sci. Technol. 25063001

[29] delaMata M, Zhou X, Furtmayr F, Teubert J, Gradecăk S, Eickhoff M, Fontcuberta i Morral A and Arbiol J 2013 J. Mater. Chem. C 14300

[30] Arbiol J, de la Mata M, Eickhoff M and Morral AF 2013 Mater. Today 16213

[31]Krogstrup P, Jørgensen HI, Johnson E, Madsen MH, Sørensen CB, Morral AF, Aagesen M, Nygård J and Glas F 2013 J. Phys. D: Appl. Phys. 46313001

[32]Lapierre RR, Chia ACE, Gibson SJ, Haapamaki CM, Boulanger J, Yee R, Kuyanov P, Zhang J, Tajik N, Jewell N and Rahman KMA 2013 Phys. Status Solidi RRL 7815

[33]Hyun JK, Zhang S and Lauhon LJ 2013 Annu. Rev. Mater. Res. 43451

[34]Royo M, De Luca M, Rurali R and Zardo I 2017 J. Phys. D: Appl. Phys. 50143001

[35]Gûniat L, Caroff P and Fontcuberta i Morral A 2019 Chem. Rev. 1198958

[36] McIntyre PC and Fontcuberta i Morral A 2020 Materials Today Nano 9100058

[37]Dubrovskii VG 2014 Nucleation theory and growth of nanostructures edited by Springer doi 10.1007/978-3-642-39660-1 [38] Shaw DW 1970 J. Electrochem. Soc. 117683

[39] Mizumo O and Watanabe H 1975 J. Crystal Growth 30240 [40]Hollan L, Durant JM and Cadoret R 1977 J. Electrochem. Soc. 124135 
[41] Grüter K, Deschler M, Jürgensen H, Beccard R and Balk P 1989 J. Crys. Growth 94607

[42] Morales AM and Lieber CM 1998 Science 279208

[43]Harrous M, Chaput L, Bendraoui A, Cadoret M, Pariset C and Cadoret R 1988 J. Crys. Growth 92423

[44]Gil E, André Y, Cadoret R and Trassoudaine A 2015 Handbook of Crystal Growth (Second Edition - Kuech) 51

[45]Pimpinelli A, Cadoret R, Gil-Lafon E, Napierala J and Trassoudaine A 2003 J. Cryst. Growth 2581

[46]Gil-Lafon E, Napierala J, Pimpinelli A, Cadoret R, Trassoudaine A and Castelluci D 2003 J. Cryst. Growth 25814

[47] Stringfellow GB 1991 J. Crys. Growth 1151

[48]Park W, Zheng G, Jiang X, Tian B and Lieber CM 2008 Nano Lett. 83004

[49]Cui Y, Wei Q, Park H and Lieber CM 2001 Science 2931289

[50]Joyce HJ, Gao Q, Hoe Tan H, Jagadish C, Kim Y, Fickenscher MA, Perera S, Hoang TB, Smith LM, Jackson HE, Yarrison-Rice JM, Zhang X and Zou J Nano Lett. 20099695

[51]Gil E, André Y, Ramdani MR, Fontaine C, Trassoudaine A and Castelluci D 2013 J. Crys. Growth 38093

[52] Gil-Lafon E, Napierala J, Castelluci D, Pimpinelli A, Cadoret R and Gerard B 2001 J. Crys. Growth 222482

[53]Ramdani MR, Gil E, André Y, Trassoudaine A, Castelluci D, Paget D, Rowe ACH and Gérard 2007 B J. Crys. Growth 306111 [54]Plante MC and Lapierre RR 2006 J. Crys. Growth 286394

[55]Piccin M, Bais G, Grillo V, Jabeen F, De Franceschia S, Carlinoa E, Lazzarino M, Romanato F, Businaro L, Rubini S, Martelli F and Franciosi A 2007 Physica E 37134

[56]Ihn SG and Song JI 2007Nanotechnology 18355603

[57] Tchernycheva M, Travers L, Patriarche G, Glas F, Harmand JC, Cirlin GE and Dubrovskii VG 2007 J. Appl. Phys. 102094313

[58] Jensen LE, Bjork MT, Jeppesen S, Persson AI, Ohlsson BJ and Samuelson L 2004 Nano Lett. 41961

[59] Sivakov V, Heyroth F, Falk F, Andr G and Christiansen S 2004 J. Crys. Growth 272167

[60]Kuykendall T, Pauzauskie PJ, Zhang Y, Goldberger J, Sirbuly D, Denlinger J and Yang P 2004 Nature Mat. 3524

[61]Joyce HJ, Gao Q, An HH, Jagadish C, Kim Y, Zhang X, Guo Y and Zou J. 2007 Nano Lett. 7921

[62] Skold N, Wagner JB, Karlsson G, Hernan T, Seifert W, Pistol ME and Samuelson L 2007 Nano Lett. 122743

[63]Johansson J, Karlsson LS, Svensson CPT, Martensson T, Wacaser BA, Deppert K, Samuelsson L and Seifert W 2006 Nature Mat. 5574

[64]Paiano P, Prete P, Speiser E, Lovergine N, Richter W, Tapfer L and Mancini AM 2007 J. Crystal. Growth 298620

[65]Bhunia S, Kawamura T, Fujikawa S, Nakashima H, Furukawa K, Torimitsu K and Watanabe Y 2004 Thin Solid Films 464-465 244

[66]Ohlsson BJ, Björk MT, Magnusson MH, Deppert K, Samuelson L and Wallenberg LR 2001 Appl. Phys. Lett. 333579

[67] Samuelson L, Thelander C, Björk MT, Borgström M, Deppert K, Dick KA, Hansen AE, Martensson T, Panev N, Persson AI, Seifert W, Skold N, Larsson MW and Wallenberg LR 2004 Physica E 25 313

[68] Martensson T, Calberg P, Borgström M, Montelius L, Seifert W and Samuelson L 2004 Nano Lett. 4699

[69]Wallentin J, Ek M, Wallenberg LR, Samuelson L, Deppert K and Borgstrom M T 2010 Nano Lett. 104807

[70]Huang H, Ren X, Ye X, Guo J, Wang Q, Zhang X, Cai S and Huang Y 2010 Nanotechnology 21475602

[71] Shtrikman H, Popovitz-Biro R, Kretinin A and Heiblum M 2009 Nano Lett. 9215
[72]Ren X, Huang H, Dubrovskii VG, Sibirev NV, Nazarenko MV, Bolshakov AD, Ye S, Wang Q, Huang Y, Zhang X, Guo J and Liu X 2011 Semicond. Sci. Technol. 26014034

[73] Wilhelm C, Larrue A, Dai X, Migas D and Soci C Nanoscale 201241446

[74] Johansson J, Bolinsson J, Ek M, Caroff P and Dick KA 2012 ACS Nano 66142

[75]Glas F, Harmand JC and Patriarche G 2007 Phys. Rev. Lett. 99 146101

[76] Galicka M, Bukala M, Buczko R and Kacman P 2008 J. Phys.: Condens. Matter 20454226

[77]Dubrovskii VG and Sibirev NV 2008 Phys. Rev. B 77035414

[78]Dick KA, Caroff P, Bolinsson J, Messing ME, Johansson J, Deppert K, Wallenberg LR and Samuelson L 2010 Semicond. Sci. Technol. 25024009

[79] Joyce HJ, Wong-Leung J, Gao Q, Tan HH and Jagadish C 2010 Nano Lett. 10908

[80]Spirkoska D, Arbiol J, Gustafsson A, Conesa-Boj S, Glas F, Zardo I, Heigoldt M, Gass MH, Bleloch AL, Estrade S, Kaniber M, Rossler J, Peiro F, Morante JR, Abstreiter G, Samuelson L and Fontcuberta i Morral1A 2009 Phys. Rev. B 80245325

[81]Lehmann S, Wallentin J, Jacobson D, Deppert K and Dick KA 2013 Nano Lett. 134099

[82]Lehmann S, Jacobsson D and Dick KA 2015 Nanotechnology 26 301001

[83]Lezec HJ, Ahopelto J, Usui A and Ochiai Y 1993 Jpn. J. Appl. Phys. 326251

[84] Ahopelto J, Lezec H, Ochiai Y, Usui A and Sakaki H 1994 Appl. Phys. Lett. 64499

[85] Messmer ER, Lourdudoss S, Ahopelto J, Lipsanen H, Hieke K, Wesström JO, Reithmaier JP, Kerkel K, Forchel A, Seifert W, Carlsson N and Samuelson L 1998 Materials Science and Engineering B51 238

[86]Sun YT,Rodriguez Messmer E, Lourdudoss S, Ahopelto J, Rennon S, Reithmaier JP and Forchel A 2001 Appl. Phys. Lett. 79 1885

[87]Ramdani MR, Gil E, Leroux Ch, André Y, Trassoudaine A, Castelluci D, Bideux L, Monier G, Robert-Goumet and Kupka R 2010 Nano Lett. 101836

[88] Andre Y, Lekhal K, Hoggan P, Avit G, Cadiz F, Rowe A, Paget D, Petit E, Leroux C, Trassoudaine A, Ramdani MR, Monier G, Colas D, Ajib R, Castelluci D and Gil E 2014 The Journal of Chemical Physics 140194706

[89]Dubrovskii VG, Soshnikov IP, Cirlin GE, Tonkikh AA, Samsonenko YB, Sibirev NV and Ustinov VM 2004 Phys. Stat. Sol. B $241 \mathrm{R} 30$

[90] Shtrikman H, Popovitz-Biro R, Kretinin A, Houben L, Heiblum M, Bukala M, Galicka M, Buczko R and Kacman P 2009 Nano Lett. 91506

[91]Dubrovskii VG, Cirlin GE, Sibirev NV, Jabeen F, Harmand JC and Werner P 2001 Nano Lett. 111247

[92]Cirlin GE, Dubrovskii VG, Samsonenko Yu B, Bouravleuv AD, Durose K, Proskuryakov Yu Yu, Mendes B, Bowen L, Kaliteevski MA, Abram RA and Zeze D 2010 Phys. Rev. B 82035302

[93]Krogstrup P, Popovitz-Biro R, Johnson E, Madsen MH, Nyga_rd $\mathrm{J}$ and Shtrikman H 2010 Nano Lett. 104475

[94]Zamani M, Tütüncüoglu G, Marti-Sanchez S, Francaviglia L, Güniat L, Ghisalberti L, Potts H, Friedl M, Markov E, Kim W, Leran JB, Dubrovskii VG, Arbiol J and Fontcuberta i Morral A 2018 Nanoscale 1017080

[95]Gil E, Dubrovskii VG, Avit G, Andre Y, Leroux C, Lekhal K, Grecenkov J, Trassoudaine A, Castelluci D, Monier G, Ramdani RM, Robert-Goumet C, Bideux L, Harmand JC and Glas F 2014 Nano Lett. 143938 
[96] Sibirev NV, Timofeeva MA, Bolshakov AD, Nazarenko MV and Dubrovskii VG 2010 Phys. Solid State 521531

[97]Rosini M and Magri R 2010 Nano Lett. 46021

[98]Pankoke V, Kratzer P and Sakong S 2011 Phys. Rev. B 84 075455

[99]Akiyama T, Sano K, Nakamura K and Ito T 2006 Jap. J. of Applied Physics $\mathbf{4 5}$ L275

[100] Massalski TB 1990 Binary alloy phase diagrams American Society for Metals

[101] Dubrovskii VG 2014 Appl. Phys. Lett. 104053110

[102] Glas F, Ramdani MR, Patriarche G and Harmand JC 2013

Phys. Rev. B $\mathbf{8 8} 195304$

[103] Deppert K, Borgström MT, Samuelson L, Dick KA, Johansson J and Wacaser BA 2009 Adv. Mater. 21153

[104] Jacobsson D, Panciera F, Tersoff J, Reuter MC, Lehmann S, Hofmann S, Dick KA and Ross FM 2016 Nature 531317

[105] Harmand JC, Patriarche G, Glas F, Panciera F, Florea I, Maurice JL, Travers L and Ollivier Y 2018 Phys. Rev. Lett. 121 166101

[106] Dubrovskii V G, Cirlin G E and Ustinov V M 2009

Semiconductors $\mathbf{4 3} 1539$

[107] Harmand JC, Patriarche G, Ṕ́-Laperne N, Mrat-Combes MN, Travers L and Glas F 2005 Appl. Phys. Lett. 871

[108] Davydok A, Breuer S, Biermanns A, Geelhaar L and Pietsch U 2012 Nanoscale Res. Lett. 71

[109] Bryllert T, Wernersson LE, Löwgren T and Samuelson L 2006 Nanotechnology 17227

[110] Seifert W, Borgström M, Deppert K, Dick KA, Johansson J, Larsson MW, Mårtensson T, Skold N, Svensson CPT, Wacaser BA, Wallenberg LR and Samuelson L 2004 J. Cryst. Growth 272211

[111] Plante MC, Garrett J, Ghosh SC, Kruse P, Schriemer H, Hall T and LaPierre RR 2006 Appl. Surf. Sci. 2532348

[112] Hijazi H, Leroy F, Monier G, Grégoire G, Gil E, Trassoudaine A, Dubrovskii VG, Castelluci D, Goktas NI, LaPierre RR, André Y and Robert-Goumet C 2020 The Journal of Physical Chemistry 124 11946

[113] Rath A, Dash JK, Juluri R R, Rosenauer A, Schoewalter M and Satyam PV 2012 J. Appl. Phys. 111064322

[114] Matteini F, Dubrovskii VG, Rüffer D, Tütüncüołlu G, Fontana Y and Morral A F I 2015 Nanotechnology 26105603 [115] Dubrovskii VG, Xu T, Álvarez AD, Plissard SR, Caroff P, Glas F and Grandidier B 2015 Nano Lett. 155580

[116] Kim W, Dubrovskii VG, Vukajlovic-Plestina J, Tütüncüoglu G, Francaviglia L, Güniat L, Potts H, Friedl M, Leran JB and Fontcuberta I Morral A 2018 Nano Lett. 1849

[117] Tauchnitz T, Nurmamytov T, Hübner R, Engler M, Facsko S, Schneider H, Helm M and Dimakis E 2017 Cryst. Growth Des. 17 5276

[118] Hijazi H, Dubrovskii VG, Monier G, Gil E, Leroux C, Avit G, Trassoudaine A, Bougerol C, Castellucci D, Robert-Goumet C and André Y 2018 J. Phys. Chem. C 12219230

[119] Matteini F, Tütüncüoglu G, Potts H, Jabeen F and Fontcuberta I Morral A 2015 Cryst. Growth Des. 153105

[120] Khorenko V, Regolin I, Neumann S, Prost W, Tegude FJ and Wiggers H 2004 Appl. Phys. Lett. 856407

[121] Chuang LC, Moewe M, Chase C, Kobayashi NP, ChangHasnain C and Crankshaw S 2007 Appl. Phys. Lett. 90043115 [122] Hijazi H, Monier G, Gil E, Trassoudaine A, Bougerol C, Leroux C, Castellucci D, Robert-Goumet C, Hoggan PE, André Y, Isik Goktas N, Lapierre RR and Dubrovskii VG 2019 Nano Lett. 19 4498

[123] Hilse M, Ramsteiner M, Breuer S, Geelhaar L and Riechert H 2010 Appl. Phys. Lett. 962008
[124] Ketterer B, Mikheev E, Uccelli E and Fontcuberta I Morral A 2010 Appl. Phys. Lett. 97223103

[125] Dufouleur J, Colombo C, Garma T, Ketterer B, Uccelli E, Nicotra M and Fontcuberta I Morral A 2010 Nano Lett. 101734 [126] Arab S, Yao M, Zhou C, Daniel Dapkus P and Cronin S B 2016 Appl. Phys. Lett. 108182106

[127] Fischer F, Schuh D, Bichler M, Abstreiter G, Grayson M and Neumaier K 2005 Appl. Phys. Lett. 861

[128] Glas F 2017 Cryst. Growth Des. 174785

[129] Dong Z, Andre Y, Dubrovskii V, Bougerol C, Monier G, Ramdani R, Trassoudaine A, Leroux C, Castelluci D and Gil E 2016 Proceedings - 2016 International Conference Laser Optics, LO 2016

[130] Bale CW, Bélisle E, Chartrand P, Decterov SA, Eriksson G, Hack K, Jung I H, Kang Y B, Melançon J, Pelton AD, Robelin C and Petersen S 2009 Calphad Comput. Coupling Phase Diagrams Thermochem. 33295

[131] Colombo C, Spirkoska D, Frimmer M, Abstreiter G and Fontcuberta I Morral A 2008 Phys. Rev. B - Condens. Matter Mater. Phys. 77

[132] Matteini F, Tütüncüołlu G, Rüffer D, Alarcón-Lladó E and Fontcuberta I Morral A 2014 J. Cryst. Growth 404246

[133] Priante G, Ambrosini S, Dubrovskii V G, Franciosi A and Rubini S 2013 Cryst. Growth Des. 133976

[134] Munshi A M, Dheeraj D L, Fauske V T, Kim D C, Huh J,

Reinertsen J F, Ahtapodov L, Lee K D, Heidari B, Van Helvoort A

T J, Fimland B O and Weman H 2014 Nano Lett. 14960

[135] Fontcuberta i Morral A, Maslov C, Colombo C, Abstreiter G, Arbiol J and Morant JR 2008 Appl. Phys. Lett. 92063112

[136] Tersoff J 2015 Nano Lett. 156609

[137] Chatillon C and Chatain D 1995 J. Cryst. Growth 15191

[138] Dong Z, André Y, Dubrovskii V G, Bougerol C, Leroux C,

Ramdani M R, Monier G, Trassoudaine A, Castelluci D and Gil E 2017 Nanotechnology 281

[139] Dubrovskii V G 2016 J. Cryst. Growth 44062

[140] Gorji Ghalamestani S, Berg M, Dick K A and Wernersson L E 2011 J. Cryst. Growth 33212

[141] Gupta N, Song Y, Holloway G W, Sinha U, Haapamaki C M, Lapierre R R and Baugh J 2013 Nanotechnology 24225202

[142] Lapierre R R, Robson M, Azizur-Rahman K M and Kuyanov P 2017 J. Phys. D. Appl. Phys. 50123001

[143] Holloway G W, Haapamaki C M, Kuyanov P, LaPierre R R and Baugh J 2016 Semicond. Sci. Technol. 311

[144] Anyebe E A 2017 Appl. Nanosci. 7365

[145] Grap T, Rieger T, Blömers C, Schäpers T, Grützmacher D

and Lepsa M I 2013 Nanotechnology 24335601

[146] Biermanns A, Dimakis E, Davydok A, Sasaki T, Geelhaar L, Takahasi M and Pietsch U 2014 Nano Lett. 146878

[147] Koblmüller G, Hertenberger S, Vizbaras K, Bichler M, Bao F, Zhang J P and Abstreiter G 2010 Nanotechnology 21365602 [148] Dick KA, Deppert K, Samuelson L and Seifert W 2007 J. Cryst. Growth 298631

[149] Mandl B, Stangl J, Mårtensson T, Mikkelsen A, Eriksson J, Karlsson L S, Bauer G, Samuelson L and Seifert W 2006 Nano Lett. 61817

[150] Soo MT, Zheng K, Gao Q, Tan HH, Jagadish C and Zou J 2016 Nano Lett. 164189

[151] Khayrudinov V, Remennyi M, Raj V, Alekseev P, Matveev B, Lipsanen H and Haggren T 2020 ACS Nano 147484

[152] Gomes U P, Ercolani D, Zannier V, Battiato S, Ubyivovk E, Mikhailovskii V, Murata Y, Heun S, Beltram F and Sorba L 2017 Nanotechnology 28065603

[153] Björk M T, Schmid H, Breslin C M, Gignac L and Riel H 2012 J. Cryst. Growth 34431 
[154] Tomioka K, Motohisa J, Hara S and Fukui T 2008 Nano Lett. 83475 